Water Management

Volume 164 Issue WM1

Modelling phytoplankton dynamics in a complex estuarine system

Nash, Hartnett and Dabrowski

ice | proceedings
Proceedings of the Institution of Civil Engineers

Water Management 164 January 2011 Issue WM1

Pages 35-54 doi: 10.1680/wama.800087

Paper $\mathbf{8 0 0 0 8 7}$

Received 27/08/2008

Published online 18/11/2010

Keywords: hydrology \& water resource/mathematical modelling/

pollution

Institution of Civil Engineers (c) 2011

\title{
Modelling phytoplankton dynamics in a complex estuarine system
}

\section{Stephen Nash}

Lecturer, Civil Engineering, College of Engineering and Informatics, National University of Ireland, Galway, Ireland

\section{Michael Hartnett}

Lecturer, Civil Engineering, College of Engineering and Informatics, National University of Ireland, Galway, Ireland
Tomasz Dabrowski

Postdoctoral Researcher, Civil Engineering, College of Engineering and Informatics, National University of Ireland, Galway, Ireland

The primary objective of this research was to develop a generic methodology for numerical modelling of the water quality within estuarine systems; in particular, this research focused on modelling nutrient dynamics and phytoplankton growth. This paper presents details of the developed modelling methodology and its application to Cork Harbour, an Irish waterbody that regularly experiences algal blooms. Input data requirements and, in particular, an innovative method for the determination of spatially varying initial conditions are presented. Phytoplankton dynamics are highly dependent on light intensity; a novel formulation for the light intensity component of the phytoplankton growth module was therefore developed and implemented in the model. The formula, which relates light intensity to turbidity and chlorophyll-a concentrations based on field data, is shown to achieve good results. Phytoplankton predictions were validated in an unusual but very effective manner using remote sensing techniques. A flushing module was included in the model to provide insights into transport processes. The paper demonstrates how simple flushing models may be used as a more cost-effective alternative to full water quality models for identification of potential eutrophic waters. Results from the Cork Harbour model are used throughout to demonstrate the effectiveness of the modelling methodology.

\section{Introduction}

Estuaries and coastal plains are natural environments that enable anthropogenic activities to flourish. Access to trade routes and the availability of receiving waters for large volumes of waste, often situated in highly scenic locations, historically attracted people to these locations and continues to do so. Today, more than half of the world's population (in excess of 3 billion people) live along a coastline or within $250 \mathrm{~km}$ of one (De Souza, 2004). Currently, anthropogenic activities exacerbate naturally occurring water quality related problems in estuaries. Despite significant efforts to improve estuarine and coastal water quality, the European Environment Agency (EEA, 2001) is concerned that eutrophication of coastal waters is one of the major environmental problems across Europe.

Considerable global efforts have been expended in developing techniques that can be used to assist in managing estuarine water quality. For example, instrumentation for measuring water quality parameters has been developed, field sampling protocols have been established, laboratory accreditation implemented and water quality models improved. Estuarine models were initially developed to predict water circulation patterns resulting from tides, winds, pressure fields and solar heating, but over the past two decades or so, significant research has resulted in more sophisticated models that have proved to be useful tools for both hindcasting and forecasting water quality events. Many different surface water quality modelling 'packages' are now available and widely used for management and research purposes (e.g. Divast, Caedym, RCA, Roms, EFDC and Mike21).

Numerical models facilitate simultaneous analysis of dominant water quality processes that prevail in surface waters. Models enable the determination of hydrodynamic regimes and nutrient budgets. They also enable investigations into cause-effect relationships and impact assessments of changes in the local environment. However, the water quality cycle and, in particular, the phytoplankton cycle are extremely complex processes to model numerically (Hipsey et al., 2007). Coupled with this is the fact that the accurate formulation of basic physical and chemical mechanisms, though essential, is no guarantee of good model predictions if sufficient data are not available to estimate nutrient inputs, rate constants, coefficients and baseline conditions. Therefore, a water quality study requires a holistic approach to modelling if any satisfactory degree of accuracy of model predictions is to be achieved.

The authors have developed an integrated measuring and modelling approach to estuarine water quality assessment. Figure 1 schematically illustrates the main features of the methodology developed. One of the most unique features of this research was 


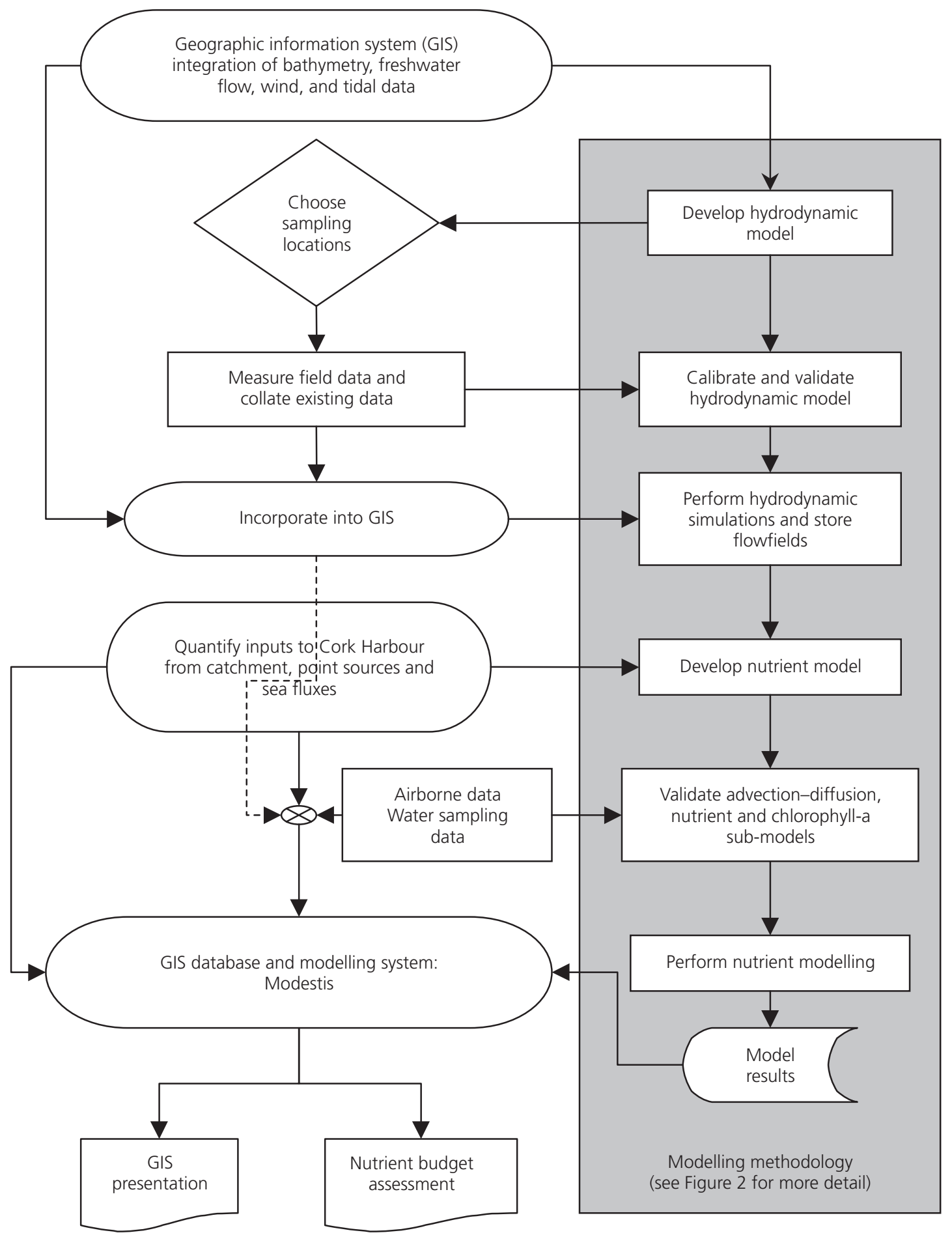

Figure 1. Integrated measurement and modelling methodology

the interdisciplinary approach taken; the project team included numerical modellers, geographers, physicists, and earth and marine scientists. This approach enabled the collation of comprehensive datasets for the study area through a variety of means including traditional field sampling and newer remote sensing techniques. The datasets were subsequently interpreted and analysed and the results were vital to the success of the modelling component, allowing the specification of good quality boundary and initial conditions and extensive calibration and validation of the model.

There are a number of novel aspects to the modelling approach. 
(a) Relationships were developed between the concentrations of various water quality parameters and salinity based on field data. This allowed the calculation of spatially varying initial conditions for these water quality parameters, which was found to improve model accuracy and reduce model simulation times.

(b) The field data enabled the development of a site-specific light attenuation formulation for the harbour, which significantly improved model predictions of chlorophyll-a. The formulation relates light attenuation to turbidity and includes a feedback mechanism relating attenuation through the water with model predicted concentrations of chlorophyll-a; this provides a unique, temporally and spatially varying, chlorophyll-a growth rate light limiting function.

(c) A flushing module was incorporated in the model and used to calculate spatial distributions of residence times. It was found that analysis of flushing results can provide valuable information on transport pathways and potentially eutrophic waters at an early stage of a water quality study and at little additional cost

(d) The research employed a unique method of validating the primary production model using spatial distributions of chlorophyll-a measurements obtained at high and low tides from the results of the airborne remote sensing part of the project.

This paper presents details of a generic modelling methodology for the development of relatively simple, yet accurate, water quality models of estuarine systems. The methodology was applied to Cork Harbour, a brackish waterbody on the south coast of Ireland, regularly experiencing algal blooms; model results are presented to illustrate the effectiveness of the methodology. Details of the physical and chemical representations employed in the model and the associated kinetic constants and coefficients are presented and discussed in some detail, along with the important contributions of the field data. The numerical model employed for this research consists of three sub-modules - a hydrodynamic module, a solute transport module and a water quality module. Each of these modules was developed sequentially, and was extensively calibrated and validated. Predictions of hydrodynamics, salinity levels and phytoplankton obtained from the validated Cork Harbour model are presented and discussed. Details of the flushing study are also presented and the results are discussed in combination with results from the primary production simulations.

\section{Modelling methodology}

The majority of Irish estuaries are relatively shallow and vertically well mixed. For example, maximum water depths in Cork Harbour are in the region of $25-30 \mathrm{~m}$ and analysis of existing data indicated that most of the harbour was well mixed and did not exhibit large-scale vertical stratification (Costello et al., 2001). It was therefore decided that the use of a twodimensional (2D) depth-integrated modelling approach would be suitable for the development of a water quality model of such systems. The model chosen for the research was the mathematical model Divast (depth-integrated velocity and solute transport) (Falconer et al., 2001), which is a 2D, depth-integrated, timevariant model based on a finite-difference solution scheme.

The hydrodynamic module is based on the solution of the depthintegrated Navier-Stokes equations and incorporates local and advective accelerations, Coriolis forces, barotropic and free surface pressure gradients, wind action, bed resistance and a simple mixing length turbulence model. The solute transport module is based on the general depth-integrated advection-diffusion equations and includes local and advective effects, turbulent dispersion and diffusion, and wind effects. The water quality module simulates source and sink inputs and decay and kinetic transformation rates for nine water quality parameters including nitrogen, phosphorous, dissolved oxygen (DO) and phytoplankton. Details of the model formulations are presented in the following sections.

Figure 2 shows the water quality modelling methodology developed during the research, and describes particular features of the modelling component of the methodology shown in Figure 1. The modelling approach consists of four main stages that must be carried out sequentially:

(a) stage I: bathymetric module

(b) stage II: hydrodynamic module

(c) stage III: solute transport module

(d) stage IV: water quality module.

Module development within each stage requires input data and process parameters sourced from field measurements and/or literature review. Once developed, each module then requires extensive calibration and/or validation, again using datasets sourced from a combination of field measurements and the literature. A most important element of the integration of the measurement and modelling is the exchange of data between the two components; model data are used to inform the field measurement campaign and field measurements are used to improve model performance. This data exchange is evident from Figure 1.

\subsection{Hydrodynamic and solute transport modules}

The governing differential equations used by the model to determine the water surface elevation and depth-integrated velocity fields in a horizontal plane are the continuity and $x$ - and $y$ direction momentum equations. These equations are based on integrating the 3D Navier-Stokes equations over the water depth. This results in a $2 \mathrm{D}$ model that resolves variables in two mutually perpendicular horizontal directions ( $x$ and $y$ ). 


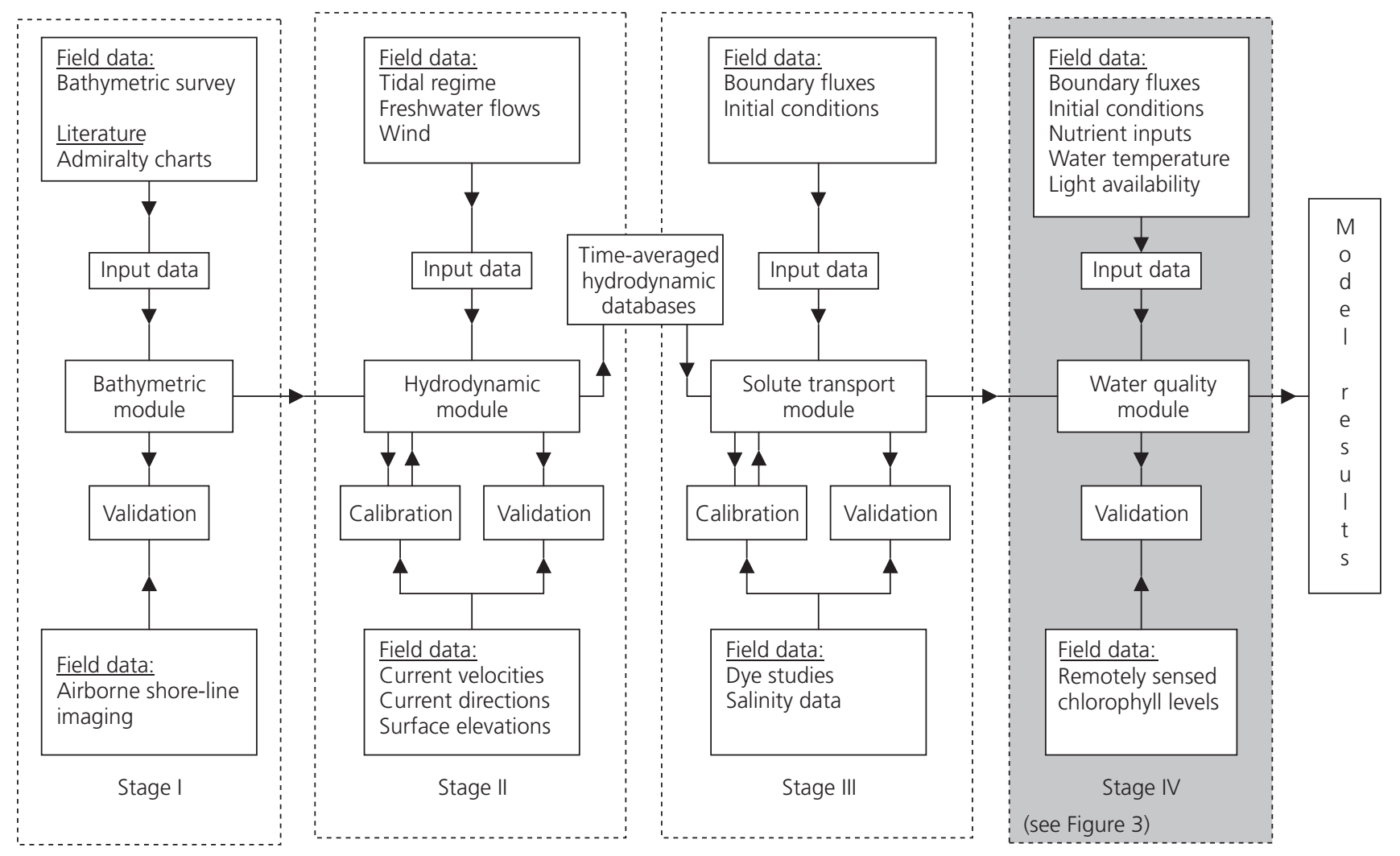

Figure 2. Modelling methodology

The continuity and momentum equations are written in a finitedifference form and are solved using the method of Gauss elimination and back-substitution. The finite-difference scheme used in the model is based upon the alternating-direction implicit (ADI) technique, which involves the subdivision of each timestep into two half-timesteps. Full details of the governing equations and the solution scheme are provided in Falconer et al. (2001).

A number of constants and coefficients are required by the model's hydrodynamic formulations. Ranges for these parameters are available in the literature; the hydrodynamic model is calibrated by 'tuning' these parameters within the recommended ranges. These parameters and associated values are presented in Section 3.

Solute transport processes are incorporated in the model through the well-established advection-diffusion equations (Falconer et al., 2001). Values for the longitudinal dispersion and turbulent diffusion coefficients may be obtained by calibrating the model against dye surveys carried out in the field. Validation of the solute transport module is best carried out by modelling salinity transport and comparing model results to field measurements. Salinity was chosen for the validation of solute transport as it is a conservative water quality parameter; as such, it is only subject to physical transportation processes and not to any chemical/ biological processes.

\subsection{Water quality module}

The phytoplankton cycle is extremely complex with many physical-chemical processes affecting the transport and interactions of phytoplankton and water quality constituents such as nutrients, DO and sediments. A decision that needs to be made by a water quality modeller is the level of detail to include; however, the relationship between level of detail and model performance is not straightforward. Added detail will necessarily reduce model speed. This may be acceptable if it leads to more accurate model results, but this cannot be guaranteed. The added detail will introduce new model parameters that in turn introduce more uncertainty to the modelling process in terms of data requirements; this may lead to less accurate model results if the data requirements cannot be fully satisfied. Figure 3 presents a schematic of the phytoplankton cycle as represented within the model; this is a more detailed version of the water quality module shown in Figure 2. The process incorporates two nutrient cycles in the form of nitrogen and phosphorous as well as the DO cycle. It provides quite a detailed phytoplankton model while keeping the number of parameters to a minimum.

The model simulates a total of nine water quality parameters and their interactions: salinity; biological oxygen demand (BOD); DO; organic, ammoniacal and nitrate nitrogen; organic phosphorous; orthophosphate; and phytoplankton (as chlorophyll-a). The kinetic formulations used to simulate these parameters are based 


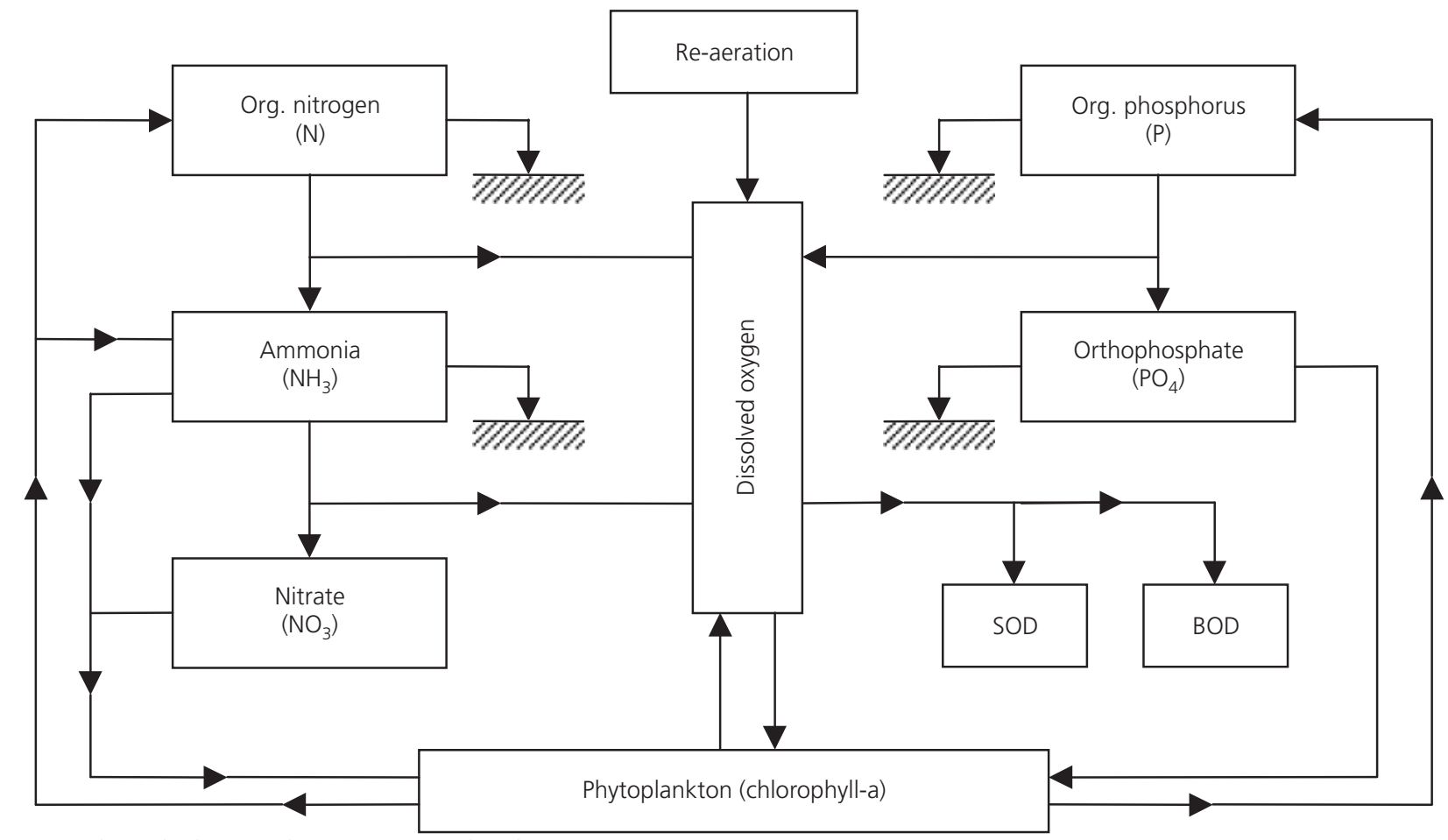

Figure 3. Phytoplankton cycle as represented within Divast

(SOD, sediment oxygen demand)

on the US Environmental Protection Agency (EPA) formulations included in the Qual2e model (Brown and Barnwell, 1987). Due to space limitations and the focus of this paper, only phytoplankton kinetics are presented here. Readers are referred to Brown and Barnwell (1987) for further details on the complete mathematical formulations used.

Phytoplankton concentrations in a natural environment depend on the plankton growth rate. It is known that this growth rate is of the order of $2 \mathrm{~d}^{-1}$ (per day) under optimal environmental conditions (Chapra, 1997). However, the growth rate cannot be modelled as a simple constant due to its dependence on environmental factors such as temperature, light and nutrient availability. The rate of change of phytoplankton concentration with respect to time $t$ may be written as:

1. $\frac{\partial C_{\mathrm{P}}}{\partial t}=\left(G_{\mathrm{P}}-D_{\mathrm{P}}-\frac{V_{\mathrm{S}}}{D}\right) C_{\mathrm{P}}$

where $C_{\mathrm{P}}$ is phytoplankton population ( $\left.\mathrm{mg} \mathrm{Chl}-\mathrm{a} / \mathrm{l}\right), G_{\mathrm{P}}$ is phytoplankton growth rate (per day), $D_{\mathrm{P}}$ is death plus respiration rate constant, $V_{\mathrm{S}}$ is settling velocity $(\mathrm{m} /$ day) and $D$ is the total water depth $(\mathrm{m})$. It should be noted that the model simulates total phytoplankton biomass by calculating concentrations of chlorophyll-a. Chlorophyll-a is a characteristic of all phytoplankton species and is used as an aggregate variable.
The phytoplankton growth rate $G_{\mathrm{P}}$ is a function of temperature, light and nutrient levels and may be expressed by Equation 2. In most cases, phytoplankton growth will be limited by insufficient light or nutrient availability; $G_{\mathrm{L}}$ and $G_{\mathrm{N}}$ are referred to as the light and nutrient limitation factors. $\mathrm{G}_{\mathrm{L}}$ is a growth-limiting factor.

2. $G_{\mathrm{P}}=\hat{G}_{\mathrm{P}} G_{\mathrm{T}} G_{\mathrm{N}} G_{\mathrm{L}}$

where $\hat{G}_{\mathrm{P}}$ is the maximum phytoplankton growth rate at $20^{\circ} \mathrm{C}$ under saturated light conditions and excess nutrients (per day) and $G_{\mathrm{T}}$ is a temperature adjustment factor. $G_{\mathrm{T}}$ is calculated using an Arrhenius-type equation incorporating the waterbody temperature while $G_{\mathrm{N}}$ is calculated using a Michaelis-Menten equation based on the levels of nitrogen and/or phosphorus that are available for phytoplankton uptake.

Most light limitation formulations consist of two components:

(a) a relationship describing the attenuation of light with depth

(b) a relationship defining the effect of the resulting light levels on algal growth and photosynthesis.

Attenuation of light occurs due to absorption and scatter by water and particles suspended in the water column. Indeed, phytoplankton itself contributes to light attenuation within the water column. 
Due to high levels of suspended solids, estuaries typically have relatively low light availability compared with open seas. Particular attention was given to the simulation of light attenuation within the model and its effects on phytoplankton production. As $G_{\mathrm{L}}$ is a growth-limiting factor, its value ranges from 0 (complete limitation) to 1 (no limitation). The following model formulation is used for $G_{L}$ :

3.

$$
G_{\mathrm{L}}=\left[\log \left(\frac{I_{\mathrm{H}}+I_{\mathrm{O}}}{I_{\mathrm{H}}+I_{\mathrm{O}}^{-K_{\mathrm{A}} H}}\right)\right] \frac{f}{K_{\mathrm{A}} H}
$$

where $I_{\mathrm{H}}$ is the light level at which phytoplankton growth is half the maximum rate $\left(\right.$ Ly/day $\left(1\right.$ Langley $\left.\left.(\mathrm{Ly})=41.84 \mathrm{~kJ} / \mathrm{m}^{2}\right)\right), I_{\mathrm{O}}$ is surface light intensity (Ly/day), $f$ is the photoperiod (sunlight fraction of day), $K_{\mathrm{A}}$ is the light attenuation coefficient and $H$ is the water depth (m).

Model predictions of chlorophyll-a from a sensitivity study carried out in a separate study of Wexford Harbour are presented in Section 3.4 and demonstrate the necessity of a site-specific light attenuation formulation in phytoplankton models. Application of the authors' modelling methodology to a new estuarine system therefore requires the development of a new light attenuation relationship specific to that estuary.

Datasets required to develop water quality modules include nutrient fluxes, initial water quality conditions, ambient environmental conditions, and kinetic transformation rates and constants. Calibration/validation datasets consisting of dye release surveys and field measurements of water quality parameters are also required. Details of these various datasets are now discussed.

Information on nutrient inputs can be compiled through a combination of field sampling and a review of existing literature and data. Nutrient inputs to estuaries are generally highly variable over time. Freshwater flow rates vary greatly between summer and winter, as do agricultural practices that contribute to catchment runoff. Thus, it is necessary to specify all nutrient input data to the model in the form of monthly averaged loads or in the form of flow-load relationships derived from data analysis. For further information on nutrient loads see Costello et al. (2001).

One of the aims of the research was to simulate realistic model start-up conditions through data assimilation. This was achieved by specifying spatially varying initial concentrations throughout the study area for each of the modelled water quality parameters; these were calculated using a set of relationships between salinity and the various water quality parameters. The relationships used were developed specifically for Cork Harbour from field data; they are presented and discussed in Costello et al. (2001). Sample initial grids for the important nutrients are shown in Section 3.
Specification of initial grids is a more accurate representation of initial conditions in a harbour than the traditional methods of specifying constant initial concentrations throughout the harbour or employing a cold-start (i.e. zero initial concentrations). The authors have found a number of benefits in the specification of initial grids. Initial grids dramatically reduce model run-time by reducing the time required for the model to reach steady state. This is desirable in the context of the timescales (weeks/months) required for primary production modelling. The accuracy of model predictions is improved as the initial grids have the effect of 'nudging' the model towards the correct solution in a data assimilation approach. In addition, the use of model salinity predictions for the computation of the initial grids means that typical initial conditions may be calculated for the model for any time of the year when combined with relevant field data.

The accuracy of the predictions of a water quality model is highly dependent on the values of the rate constants and coefficients (e.g. nitrification rates, re-aeration rates, decay rates) employed in the model's kinetic formulations. Typical values for these data can be obtained from a review of relevant literature and/or through model calibration. Table 1 lists the rate constants and coefficients required by the water quality model (values are shown for the Cork Harbour model). Typical values suggested in the literature are also presented where available.

The water quality module may be validated using field data. A unique method of model validation was used in this research: model results were compared with measurements of chlorophyll-a calculated from the results of the airborne remote sensing part of the project. This produced geo-referenced chlorophyll-a concentrations at discrete points along the flight paths of the aeroplane. The reader is directed to Costello et al. (2001) for further details of the remote sensing aspects of the research.

\subsection{Flushing study}

Hydrodynamic circulation patterns within estuaries are often quite complex and difficult to understand when limited to analysis of traditional field data measurements or model outputs such as current velocity/direction time-series or vector snapshots. In order to assist in better understanding water circulation and nutrient dynamics within an estuarine system, flushing modules can be developed using numerical models to compute flushing characteristics such as residence time. In this research, residence times $\tau_{\text {r }}$ were computed using a formula developed by Takeoka (1984):

4. $\tau_{\mathrm{r}}=\int_{0}^{\infty} r(t) \mathrm{d} t$

where $r(t)$ is the remnant function:

5. $r(t)=M(t) / M_{0}$ 
with $M(t)$ and $M_{0}$ representing the mass of dye within the region of interest at time $t$ and time 0 . The remnant function $r(t)$ denotes the decrease of the dye mass, considered as the ratio of the mass of dye whose residence time is greater than $t$ to the initial mass of dye. $r(t)$ cannot be provided arbitrarily and must be deter- mined experimentally using numerical models; in this research it was computed following Murakami (1991):

6. $r(t)=\exp \left(-A_{1} t^{B_{1}}\right)$

\begin{tabular}{|c|c|c|c|}
\hline Parameter & Value & Range & Source* \\
\hline Decay rate for BOD via de-oxygenation: per day & $0 \cdot 210$ & $(0.02-3 \cdot 4)$ & $\mathrm{BB}$ \\
\hline Temperature correction for de-oxygenation & 1.047 & 1.047 & $\mathrm{BB}$ \\
\hline Decay rate for BOD via settling loss: per day & $0 \cdot 130$ & $(-0.36-0.36)$ & $\mathrm{BB}$ \\
\hline Temperature correction for BOD via settling loss & 1.024 & 1.024 & $\mathrm{BB}$ \\
\hline Decay rate for hydrolysis of organic $\mathrm{N}$ to $\mathrm{NH}_{3}$ : per day & 0.400 & $(0.02-0.4)$ & $\mathrm{BB}$ \\
\hline Temperature correction for organic $\mathrm{N}$ hydrolysis & $1 \cdot 047$ & 1.047 & $\mathrm{BB}$ \\
\hline Decay rate for organic $\mathrm{N}$ via settling: per day & $0 \cdot 100$ & $(0.001-0.1)$ & $\mathrm{BB}$ \\
\hline Temperature correction for organic $\mathrm{N}$ via settling & $1 \cdot 024$ & 1.024 & $\mathrm{BB}$ \\
\hline Decay rate for $\mathrm{NH}_{3}$ via oxidation: per day & 1.000 & $(0 \cdot 1-1 \cdot 0)$ & BB \\
\hline Temperature correction for $\mathrm{NH}_{3}$ via oxidation & 1.083 & 1.083 & BB \\
\hline Temperature correction for re-aeration & 1.024 & 1.024 & BB \\
\hline Sediment oxygen demand (SOD) rate: $\mathrm{mg} / \mathrm{m}^{2}$ per day & $5 \cdot 000$ & $(1 \cdot 5-9 \cdot 8)$ & $\mathrm{F}$ \\
\hline Temperature correction for SOD rate & $1 \cdot 060$ & 1.060 & $\mathrm{BB}$ \\
\hline Rate of oxygen uptake per unit of $\mathrm{NH}_{3}: \mathrm{mg} \mathrm{DO} / \mathrm{mg} \mathrm{N}$ & $3 \cdot 500$ & $(3 \cdot 0-4 \cdot 0)$ & $\mathrm{BB}$ \\
\hline DO exchange coefficient for stagnant water: $\mathrm{mm} / \mathrm{h}$ & 5.000 & $5 \cdot 32$ & $\mathrm{C}$ \\
\hline Half-saturation DO limiting constant: mg/l & $2 \cdot 000$ & 2 & $\mathrm{~F}$ \\
\hline DO production per unit of chlorophyll-a: mg DO/mg Chl-a & 0.133 & $(1 \cdot 4-1 \cdot 8)$ & $\mathrm{BB}, \mathrm{B}$ \\
\hline DO uptake per unit of chlorophyll-a: mg DO/mg Chl-a & $0 \cdot 100$ & $(1 \cdot 6-2 \cdot 3)$ & $\mathrm{BB}, \mathrm{B}$ \\
\hline Max. algae growth rate at reference temperature $\left(20^{\circ} \mathrm{C}\right)$ : per day & $2 \cdot 000$ & $(1-3)$ & $\mathrm{BB}$ \\
\hline Temperature correction for max. algae growth rate & $1 \cdot 047$ & $(1 \cdot 01-1 \cdot 2)$ & B \\
\hline Half-saturation constant for light limitation: Ly/day & $6 \cdot 000$ & $(7 \cdot 8-39)$ & BB \\
\hline Rate of respiration plus excretion: per day & 0.060 & $(0.05-0 \cdot 15)$ & $\mathrm{B}, \mathrm{C}$ \\
\hline Temperature correction for respiration + excretion & 1.047 & $(1 \cdot 01-1 \cdot 2)$ & B \\
\hline Algae settling velocity: $\mathrm{m} /$ day & 0.050 & $(0.04-0.6)$ & B \\
\hline \multicolumn{4}{|l|}{ Phytoplankton death rate constant: per day } \\
\hline non-predatory mortality rate & 0.010 & $(0.01-0 \cdot 1)$ & $\mathrm{B}$ \\
\hline rate of losses due to grazing & 0.020 & - & \\
\hline Half-saturation constant for $\mathrm{N}$ : mg N/l & 0.060 & $(0.01-0 \cdot 3)$ & BB \\
\hline $\mathrm{N}$ fraction of algal chlorophyll: mg N/mg Chl-a & $7 \cdot 200$ & $(7 \cdot 2)$ & $\mathrm{B}, \mathrm{C}$ \\
\hline $\begin{array}{l}\text { Fraction of dead and respired phytoplankton recycled to organic } \mathrm{N} \text { pool: } \\
\mathrm{mg} \mathrm{N} / \mathrm{m}^{2} \text { per day }\end{array}$ & $0 \cdot 100$ & - & $\mathrm{F}$ \\
\hline $\begin{array}{l}\text { Fraction of dead and respired phytoplankton recycled to organic } \mathrm{P} \text { pool: } \\
\mathrm{mg} \mathrm{P} / \mathrm{m}^{2} \text { per day }\end{array}$ & $0 \cdot 100$ & - & $\mathrm{F}$ \\
\hline Half-saturation constant for P: mg P/l & 0.010 & $(0.001-0.05)$ & BB \\
\hline P fraction of algal chlorophyll: mg P/mg Chl-a & $1 \cdot 000$ & $(1 \cdot 0)$ & $\mathrm{B}, \mathrm{C}$ \\
\hline Hydrolysis rate for organic $\mathrm{P}$ to inorganic $\mathrm{P}$ : per day & 0.085 & $(0.01-0.7)$ & BB \\
\hline Temperature correction for organic $\mathrm{P}$ hydrolysis & $1 \cdot 047$ & 1.047 & $\mathrm{BB}$ \\
\hline Settling rate constant for organic P: per day & 0.010 & $(0.001-0.1)$ & $\mathrm{BB}$ \\
\hline Temperature correction for inorganic $\mathrm{P}$ settling rate & $1 \cdot 024$ & 1.024 & $\mathrm{BB}$ \\
\hline Settling rate constant for inorganic P: per day & 0.010 & - & $\mathrm{F}$ \\
\hline Temperature correction for inorganic $P$ settling rate & $1 \cdot 047$ & - & $\mathrm{F}$ \\
\hline
\end{tabular}

*BB, Brown and Barnwell (1987); B, Bowie et al. (1985); C, Chapra (1997); F, Falconer et al. (2001)

Table 1. Parameters used in nutrient model formulations and associated values 
This function represents the dye decay curve for a waterbody with tidal exchange. The empirical constants $A_{1}$ and $B_{1}$ depend on the shape of the decay curve and must be determined in each case. Upon determination of $A_{1}$ and $B_{1}$, Equation 4 can then be used to calculate the average residence time for the region of interest.

While the average residence time for a particular waterbody is a very useful indicator of its flushing characteristics, it is a rather general parameter since flushing rates can vary quite significantly between sub-regions. In order to visualise this phenomenon, spatial distributions of the residence time can be computed. This is done by considering each grid cell within the region of interest as a small, completely mixed reactor. Using this approach, a residence time is computed for each grid cell allowing spatial plots of residence time. These plots provide great insight into local variations in flushing times and the identification of transport pathways. Results from a flushing study of Cork Harbour are also presented in Section 3 and are compared with spatial distributions of chlorophyll-a.

\section{Cork Harbour case study: results and discussion}

Cork Harbour (Figure 4) is a large, brackish estuary on the south coast of Ireland. Located at the mouth of the River Lee, it opens onto the Celtic Sea and its $190 \mathrm{~km}$ of coastline make it one of the largest sea inlets in Ireland. It is one of the finest examples of a natural harbour in the world, and has therefore become heavily populated and industrialised. The harbour is relatively deep and long with a large surface area and drains a large freshwater catchment. The main freshwater influence is the River Lee; other freshwater discharges include the Rivers Owenacurra, Owenbuidhe and Glashaboy but their influences are relatively minor.

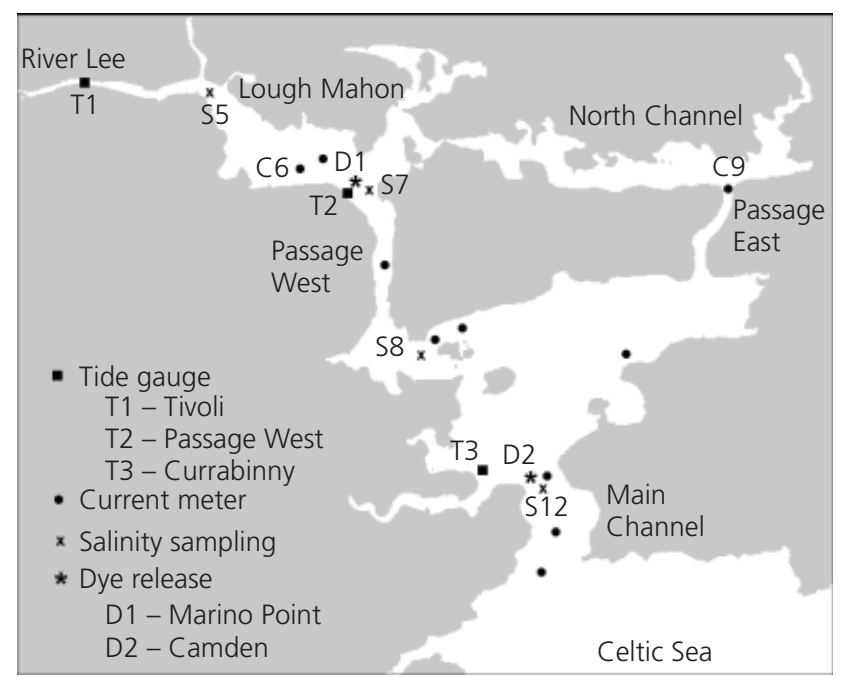

Figure 4. Cork Harbour model domain and calibration/validation locations
The harbour is macro-tidal with a maximum tidal range of $4.2 \mathrm{~m}$ and extensive mudflats exposed at low tides. The mudflats and saltmarsh regions are important ecosystems and the harbour was designated a special protection area (SPA) under the 1979 wild birds directive. Other regions within the harbour have also been designated as natural heritage area (NHAs).

Water quality in Cork Harbour is affected by large numbers of nutrient sources. More than 100 large-scale industries discharge their effluents into the harbour, including a number of large pharmaceutical plants. Many smaller industries also discharge to the sewers. Nine wastewater treatment plants discharge domestic waste to the harbour and nutrients also enter through freshwater and marine sources. As a result, a number of stretches of water within the harbour have been classified as eutrophic or potentially eutrophic by the Irish EPA. Algal blooms have been found to occur regularly, and toxic phytoplankton species (Alexandrium tamarense and Chaetoceros sp.) have also been recorded (Marine Institute, 1999). For more detailed information on the quantification of nutrient inputs to Cork Harbour see Costello et al. (2001).

A substantial proportion of the data used in this research for calibration and validation of the Cork Harbour model was obtained from the 1977 Cork Harbour pollution report (CHPR) (O’Sullivan, 1977). The report contains a detailed hydrodynamic study of the area, and includes extensive tidal elevation and current velocity measurements, results of numerous dye release surveys and a detailed salinity measurement study. The availability of such a comprehensive dataset is unusual in most modelling studies and enabled the achievement of a high degree of accuracy in model predictions. Although the CHPR was written in 1977, its results could still be used as Cork Harbour is quite stable and no appreciable variations in bathymetry occurred in the intervening period.

\subsection{Hydrodynamics}

Figure 4 shows the extent of the Cork Harbour model domain. Water depths were obtained from the relevant Admiralty charts and interpolated onto an orthogonal grid of $30 \mathrm{~m}$ resolution. These data were augmented with additional bathymetric survey data and shoreline images captured during the remote sensing section of the research. The open-sea boundary was located in the Celtic Sea while the upstream freshwater boundary on the River Lee was chosen at a location where the cross-section could be accurately defined and any effects on model predictions were minimised. The tidal data used to drive the hydrodynamic module were:

(a) mean spring tidal range $4 \cdot 2 \mathrm{~m}$

(b) mean neap tidal range $2 \cdot 1 \mathrm{~m}$

(c) tidal period $12.5 \mathrm{~h}$

(d) spring-neap tidal period $337 \cdot 5 \mathrm{~h}$. 
Table 2 lists the hydrodynamic calibration variables and the values employed in the calibrated model. Recommended values for these variables are also included. The locations of the tide gauges and current meters deployed according to the CHPR are shown in Figure 4. Figures 5 and 6 show calibration plots for spring tide water surface elevations and current velocities respectively at two of the locations shown in Figure 4. Validation plots are shown in Figures 7 and 8 for neap tide water surface elevations and current velocities at two locations. These results demonstrate that the model is capable of accurately predicting the hydrodynamic conditions within the harbour.

Further validation is presented in Figure 9, which presents comparisons of water surface elevations predicted at Tivoli (located at the mouth of the River Lee, T1 on Figure 4) and Currabinny (located close to the mouth of the estuary, T3 on Figure 4). Figure 9 shows a time lag between the occurrences of high water at these locations, occurring approximately $15 \mathrm{~min}$ later at Tivoli. This tidal pattern was also noted in the tidal survey published in the CHPR where it is stated that there is a time lag of approximately $14 \mathrm{~min}$ between the times of high water at the two sites.

\subsection{Solute transport}

To calibrate the solute transport module, two dye releases were simulated. The longitudinal dispersion and lateral turbulent diffusion coefficients were adjusted in order to achieve the best agreement between simulated and recorded dye plumes. The model values, post-calibration, and typical ranges for the dispersion/diffusion coefficients are listed in Table 2. Validation of the module was achieved by simulating salinity transport within the harbour under typical summer and winter conditions and comparing model predictions with field measurements. Two salinity simulations were carried out in order to validate the solute transport module.

\subsubsection{Dye surveys}

Two dye releases are described in the CHPR (O'Sullivan, 1977: vol. XIV) and these were used to calibrate the solute transport module. Point discharges were specified to the model replicating

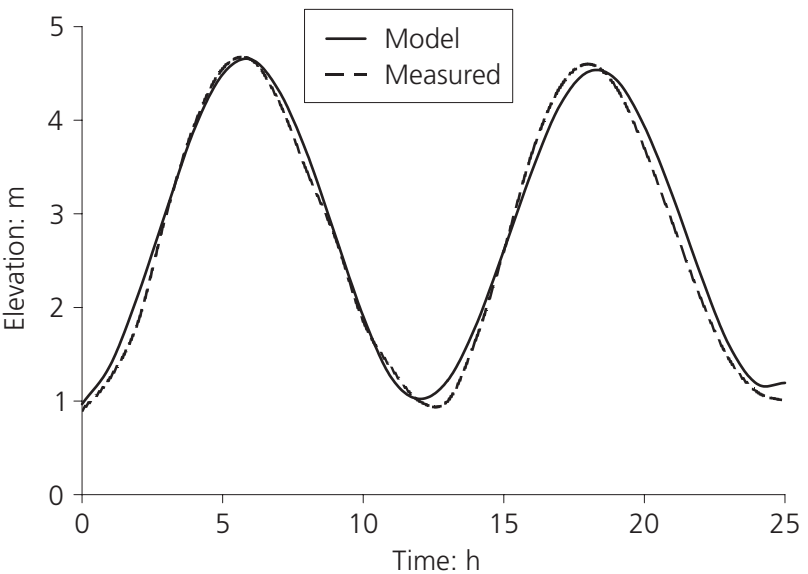

(a)

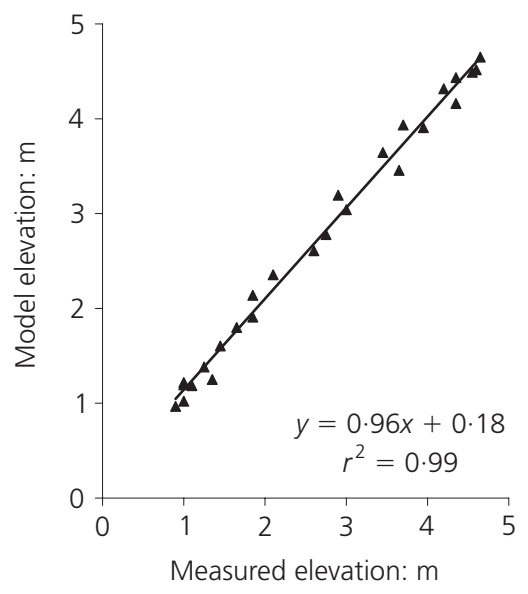

(b)

Figure 5. (a) Water surface elevation calibration for spring tide at Currabinny (T3 on Figure 4) and (b) linear regression analysis of measured and modelled data

the discharge locations in the field at Marino Point and Camden (shown in Figure 4). A discharge flow rate of 1 litre $/ \mathrm{s}$ was specified at both locations with dye inputs of $90 \mathrm{~kg} /$ day (at Marino) and $180 \mathrm{~kg} /$ day (Camden) and pumping durations of
Calibration variables
Model value
Recommended

Hydrodynamic variables

Roughness length: $\mathrm{mm}$

Kinematic viscosity: $\mathrm{m}^{2} / \mathrm{s}$

Momentum correction coefficient

Coefficient of eddy viscosity

Solute transport variables

Longitudinal dispersion coefficient

Lateral turbulent diffusion coefficient
30

$1.41 \times 10^{-6}$

1.016

1.00

$13 \cdot 00$

1.00
80

$1.31 \times 10^{-6}$ (seawater at $20^{\circ} \mathrm{C}$ )

1.016 for seventh law profile

$0.23-1.00$

$5 \cdot 93-13.00$

$0.23-1.00$

Table 2. Hydrodynamic constants and coefficients used for calibration (Falconer et al., 2001) 


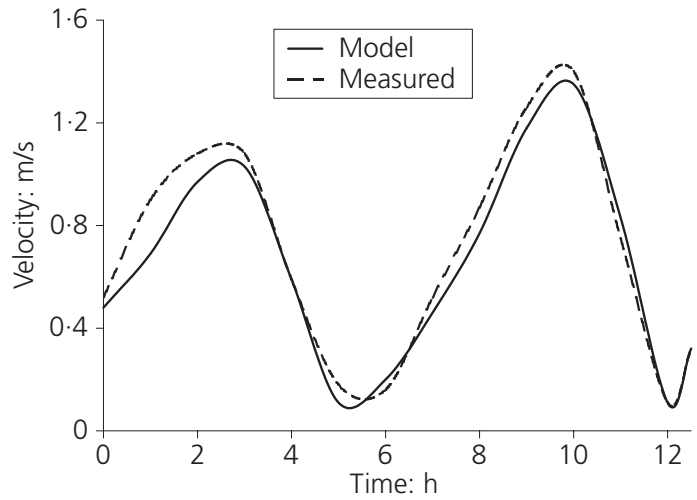

(a)

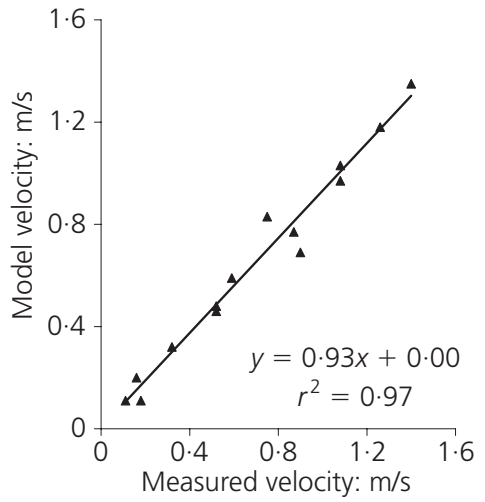

(b)

Figure 6. (a) Current velocity calibration for spring tide at C9 and (b) correlation of modelled and measured data using linear regression analysis

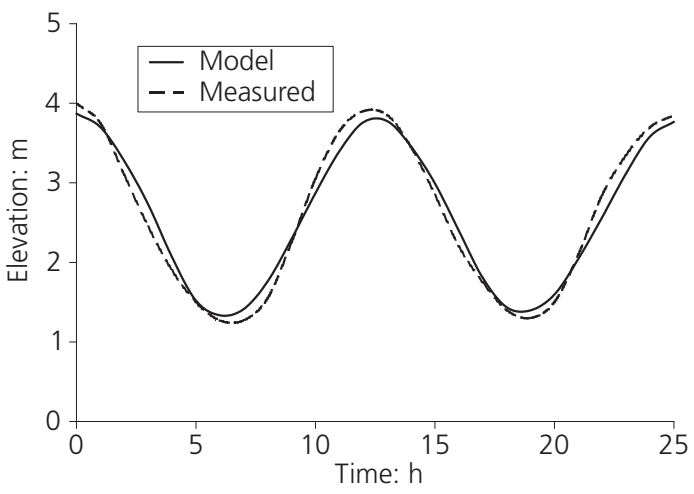

(a)

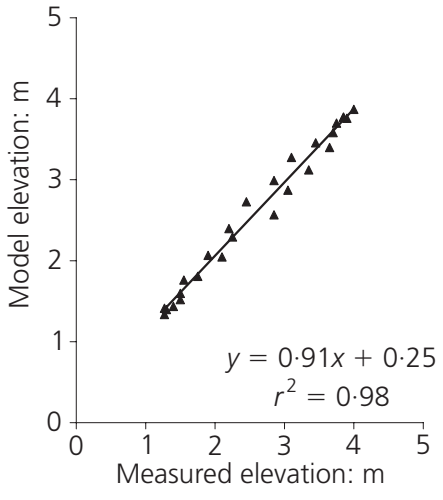

(b)

Figure 7. (a) Water surface elevation validation for neap tide at Passage West and (b) linear regression analysis of measured and modelled data

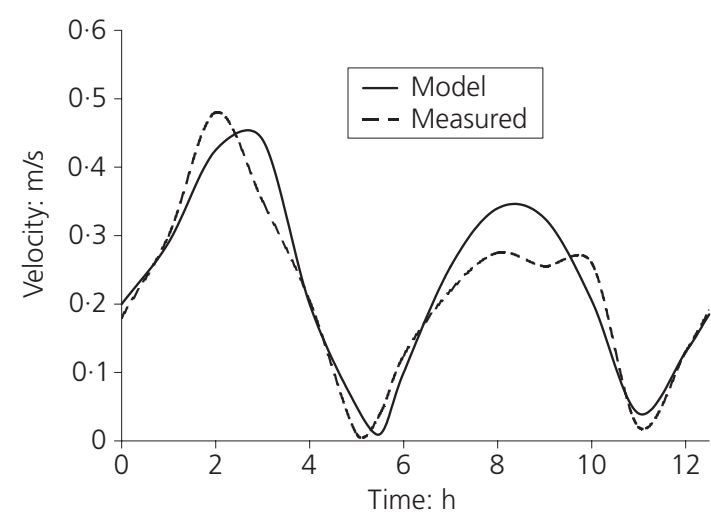

(a)

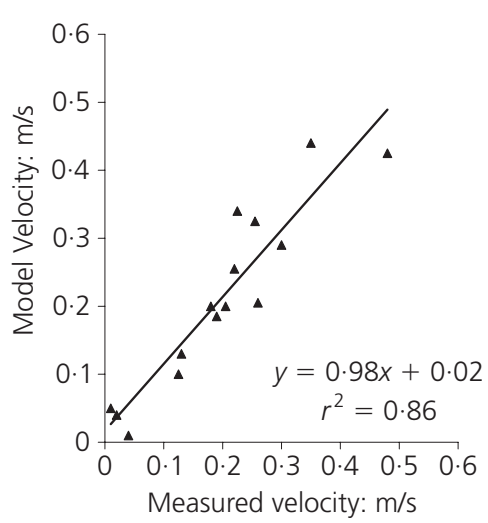

(b)

Figure 8. (a) Current velocity calibration for neap tide at C6 (see Figure 4) and (b) correlation of modelled and measured data using linear regression analysis 


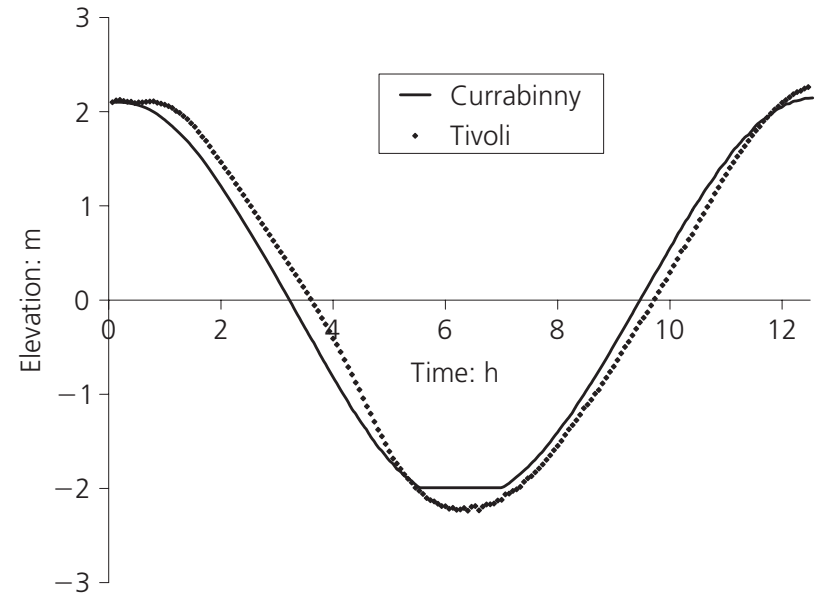

Figure 9. Comparison of model water surface elevations at Tivoli and Currabinny

4 days (Marino) and 2 days (Camden). Figure 10 shows a contour plot of the dye plume as predicted by the calibrated model for the Marino Point release at low water, 2 days after discharge began; Figure 11 shows the dye plume as recorded in the field at the corresponding time.

Comparison of Figures 10 and 11 reveals that the model results show good correlation with those of the field study, with similar plume shapes and concentration distributions evident in both figures. A linear region of high concentration was recorded in Passage West during the field survey and occurred due to ebbtide flushing of the dye from Lough Mahon. This is reproduced well by the model, with quite similar levels of dye concentration in evidence. The extent of the simulated dye plume following 2 days of tidally induced dispersion is also commensurate with

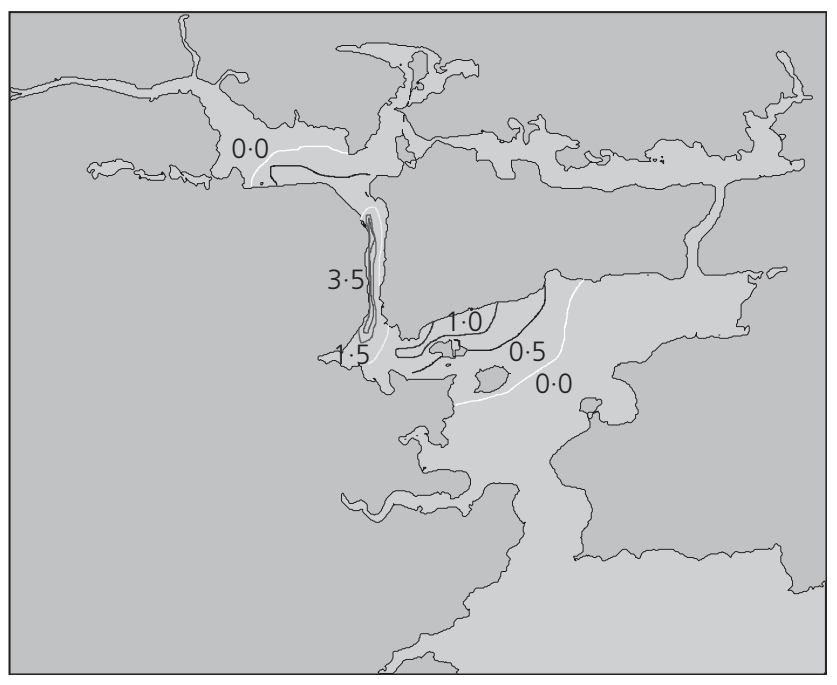

Figure 10. Dye plume predicted by the calibrated model (concentrations in $\mu \mathrm{g} / \mathrm{l}$ )

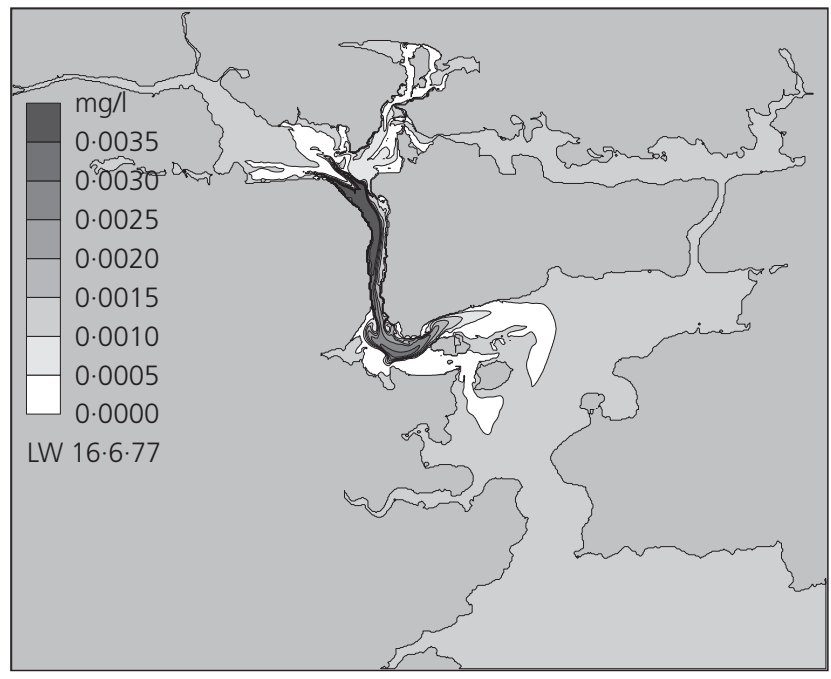

Figure 11. Dye plume recorded in the field

the field survey extent. In addition, the concentration gradients within both plumes are consistent. Similar snapshot comparisons to that presented were produced at a number of time intervals for both dye releases. These showed similar levels of agreement, indicating that the calibrated solute transport module predicted dispersion and diffusion processes within the harbour to a high degree of accuracy.

\subsubsection{Salinity simulations}

Model predictions of summer and winter salinity distribution within the harbour were compared with measured salinity values obtained from both the CHPR and field measurements. The simulations were run for the months of July and November. Ocean water entering the model domain from the Celtic Sea via the open-sea boundary was assigned a salinity of $35 \mathrm{ppt}$ (parts per thousand). Water entering the domain via the River Lee boundary was assigned a salinity of $15 \mathrm{ppt}$ for the July run and $8 \mathrm{ppt}$ for the November run. These values were obtained from field data recorded in the regions of the model boundaries. In both simulations, freshwater inflows of the main rivers were included at the appropriate monthly averaged flow rates and assigned zero salinity; the initial salinity throughout the harbour was specified as 35 ppt. Figure 12 shows the predicted salinity concentrations at points S5, S7, S8 and S12 (see Figure 4 for locations) on a spring tide for the November simulation and compares them to the corresponding maximum and minimum concentrations recorded for the same spring tide period. Again, good correlation can be observed between modelled and measured salinities. At all locations, the range of predicted concentrations over the tidal cycle is very similar to the measured range. This correlation was also observed in the July simulation results (Costello et al., 2001).

The results of the salinity modelling were also used to assess the benefits of providing accurate initial conditions in a water quality 


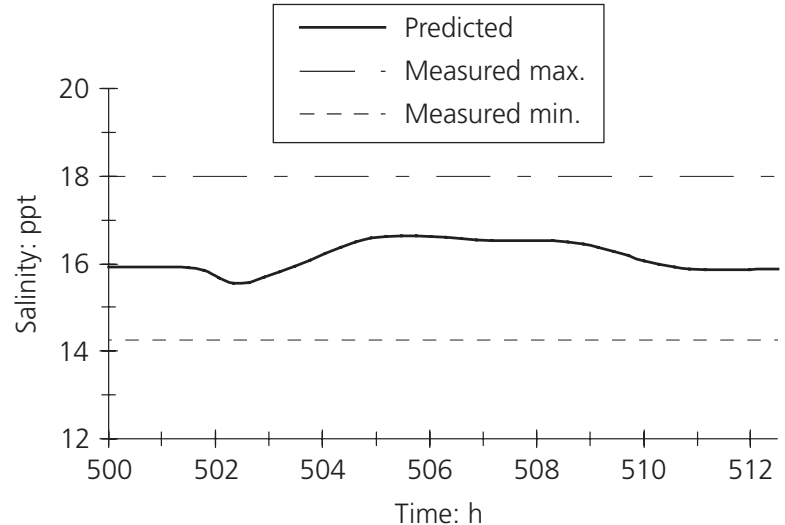

S5

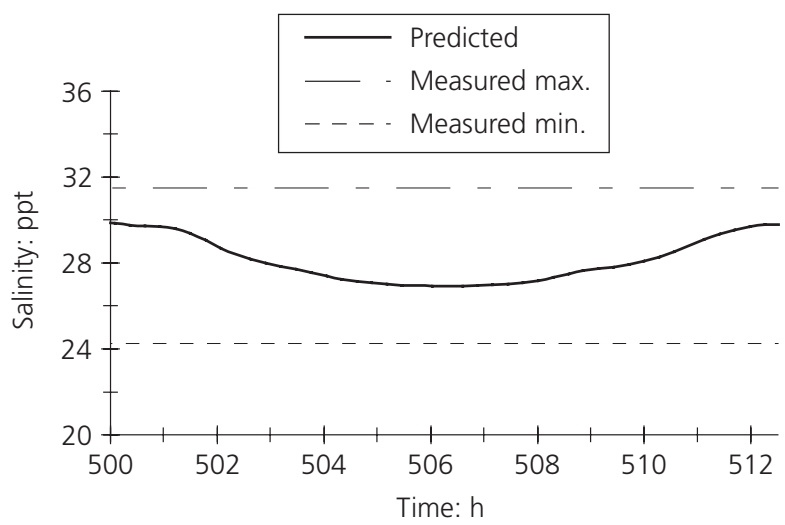

s8

Figure 12. Validation comparisons of predicted and measured salinity (November) at locations shown in Figure 4

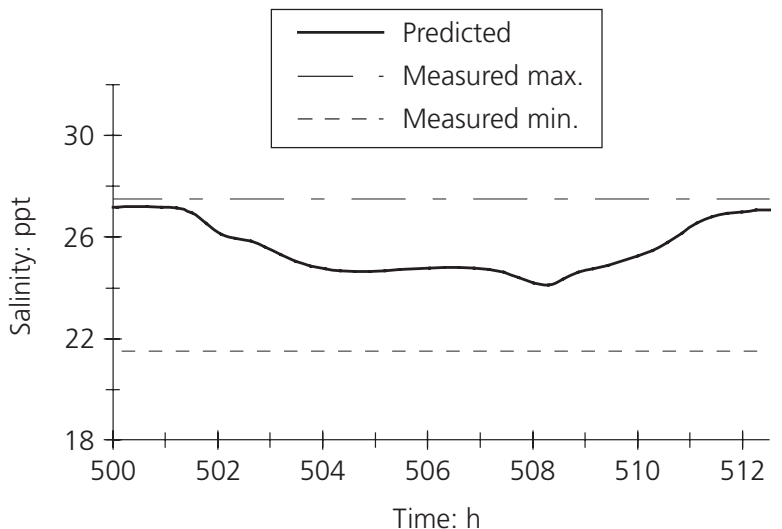

S7

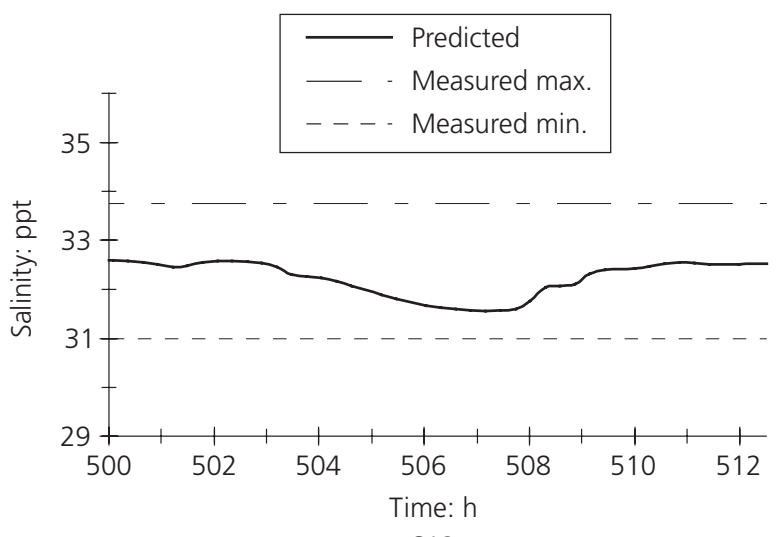

S12 model. Two separate salinity simulations were executed using different sets of initial conditions for the harbour. The aim of these simulations was twofold: firstly to determine whether the model would reach steady state regardless of initial conditions; secondly to ascertain the effect, if any, of the initial conditions on the time to steady-state predictions. The initial conditions specified were $35 \mathrm{ppt}$ salinity in one simulation (run 1) and zero salinity in the other (run 2). Figure 13 compares salinity concentrations from both simulations for the same location in Cork Harbour. It can be seen from the figure that after approximately $1100 \mathrm{~h}$ both models compute identical salinity concentrations, demonstrating that they have both reached steady state. It can also be seen that run 1 reaches steady state after approximately $900 \mathrm{~h}$ while run 2 only reaches steady state at about $1100 \mathrm{~h}$. This is a difference of $200 \mathrm{~h}$ or 8.33 days. The initial condition of $35 \mathrm{ppt}$ is much closer to the actual salinity levels at the location shown and the results show that the specification of more accurate initial conditions reduces the required computation time. It should be highlighted that the computational time saving of 8 days was achieved when modelling a single water quality parameter - a significantly greater time saving is achieved when modelling the full water quality cycle.

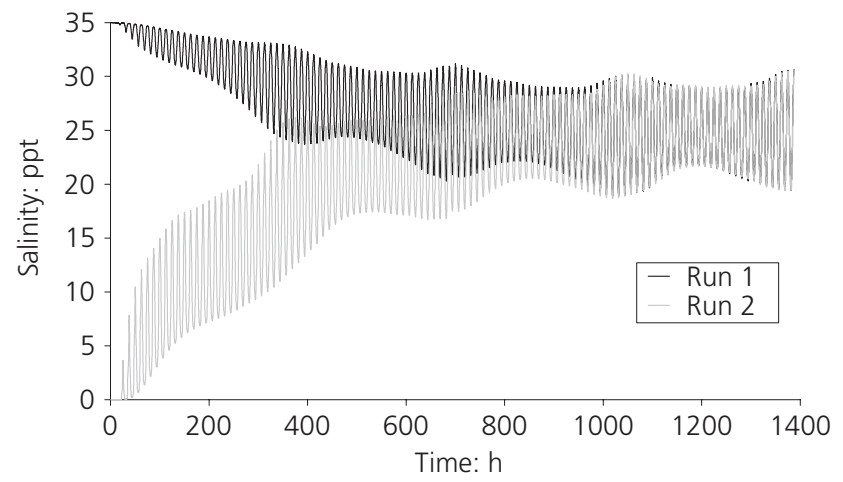

Figure 13. Salinity concentrations predicted using 35 ppt (run 1) and 0 ppt (run 2) initial conditions 


\subsection{Flushing study}

In order to assess flushing, the harbour was divided into three regions suspected of having different flushing properties: region A consisted of the entire harbour; region B comprised the semienclosed shallow North Channel section; and region $\mathrm{C}$ consisted of the main harbour including the Main Channel (see Figure 14(a)). A flushing analysis simulation was carried out for each region. For each simulation, the hydrodynamic model was run until steady-state conditions were reached; at this juncture a uniform dye concentration of $35 \mathrm{mg} / \mathrm{m}^{3}$ was specified at each wet grid cell of the region. The model was then run for a further $3000 \mathrm{~h}$.

Temporal changes in the mean dye concentrations within the regions were computed by the model and graphed to obtain the dye decay curves. The remnant function of Equation 6 was then fitted to the decay curves for each region using the least-squares method allowing the determination of the coefficients $A_{1}$ and $B_{1}$. Using Equation 4, the average residence times for each region were calculated as follows:

(a) region A, $22 \cdot 5$ days

(b) region $\mathrm{B}, 22 \cdot 2$ days

(c) region $\mathrm{C}, 12 \cdot 0$ days.

Residence times were also calculated for each grid cell within a particular region. Figure 14(b) shows the spatial distributions of residence times for each of the three regions calculated for annual averaged freshwater inflow conditions.

The average residence time for the whole harbour (region A) was found to be 22.5 days. From additional sensitivity simulations it was found that freshwater inflow was extremely important in terms of harbour flushing. When river inflows were half the annual average value, a substantial reduction in flushing was observed with the average residence time increasing from $22 \cdot 5$ to $25 \cdot 2$ days. In the absence of river discharges the average residence time increased to 36 days. This has important implications for nutrient circulation and ensuing primary production as freshwater flows are at a minimum during the critical summer months for production.

The spatial variation of residence times within the harbour provides a very good insight into hydrodynamic circulation patterns and a means of identifying possible hotspots for phytoplankton growth. From the results for region A in Figure 14(b), it is apparent that the harbour can be divided into four separate sub-regions with different flushing characteristics. The Main Channel and central section of the main harbour are well flushed with residence times in the region of 10 days; residence times elsewhere are substantially greater. Those in Passage West and Lough Mahon are in the region of 25-35 days while those in Passage East are in the region of 50-60 days. Finally, residence times in the semi-enclosed North Channel are in excess of 70 days, indicative of a poorly flushed region. The results suggest that Passage East, Passage West, Lough Mahon and North Channel in particular are prime locations for algal growth. The low flushing capacities when combined with significant sources of nutrient inputs, such as within Lough Mahon, provide optimum conditions for phytoplankton blooms. This point is revisited in the next section.

The spatial distribution plots for residence time clearly delineate areas where waters are well mixed or poorly mixed/stagnant. Figure 14(b) shows that, for region A, stagnant water is present in the eastern reaches of the Main Harbour and in the entire North Channel. The flushing analyses of regions B and C show similar trends. For the North Channel (region B) in particular, the average residence time of 22.2 days is almost identical to that of the whole harbour, 22.5 days (region A). Thus, very little exchange takes place through the narrow straits to the west and east of the channel. Analysis of Figure 14(b) identifies transport pathways that are useful in understanding hydro- and, in particular, nutrient dynamics. For example, on examination of region B it can be seen that most water is flushed out of the region from the eastern end through Passage East; therefore, nutrients entering the North Channel at the western end are more likely to accumulate to eutrophic levels. The computation and analysis of flushing characteristics offers a simple but effective method of preliminarily assessing the transport and fate of nutrients/pollutants within waterbodies without incurring the costs associated with the development of a full water quality model. The approach is also applicable to any type of waterbody from freshwater lakes to fully saline seas.

\subsection{Phytoplankton modelling results}

Following calibration and validation, the water quality model was developed and used to simulate primary production within Cork Harbour. The model was run to predict phytoplankton production for the month of September; measurements of chlorophyll-a obtained from airborne remote sensing were collected during this period.

Initial conditions were specified to the model for all nine water quality parameters. Figure 15 shows the initial grids for (a) ammoniacal nitrogen, (b) nitrate nitrogen and (c) orthophosphate that were specified for the phytoplankton simulation. The figures show that the highest concentrations of all three nutrients occur in the Lough Mahon area. Elevated levels are also in evidence in the North Channel and, to a lesser extent, in Passage East and Passage West. The reason for this is apparent from the flushing study results of the previous section where residence times were shown to be significantly greater in these areas than in the main harbour. The levels in Lough Mahon are highest due to the larger number of nutrient sources concentrated in the area.

An added benefit of using initial grids is that they may be used to give insights into the limiting nutrient for phytoplankton growth 
Modelling phytoplankton dynamics in a

complex estuarine system

Nash, Hartnett and Dabrowski

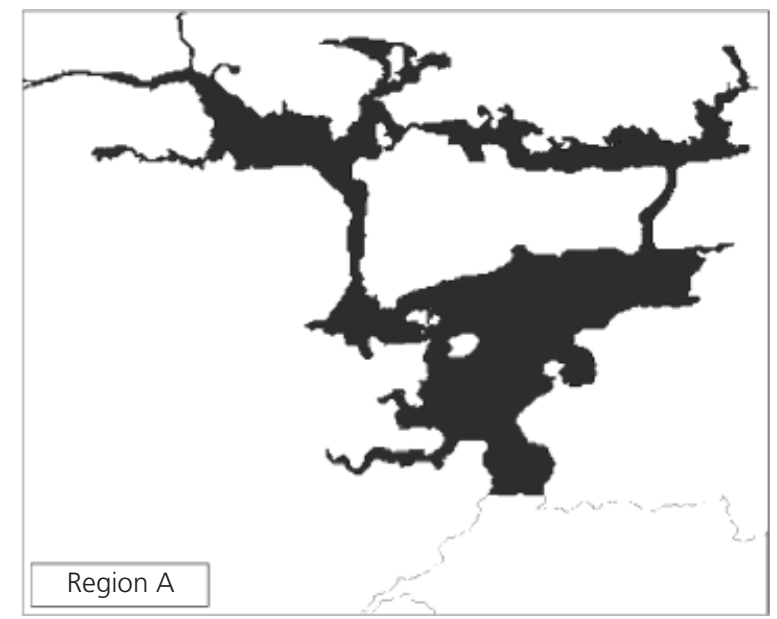

(i)

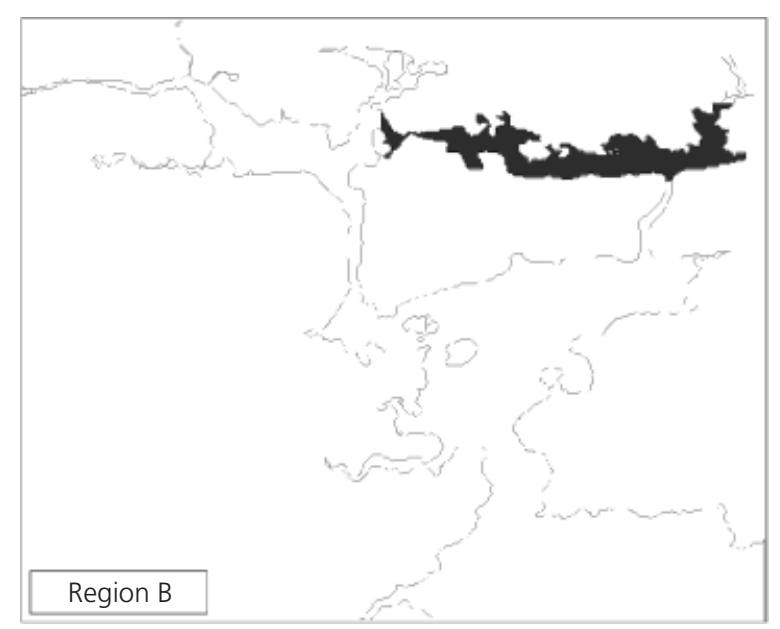

(ii)

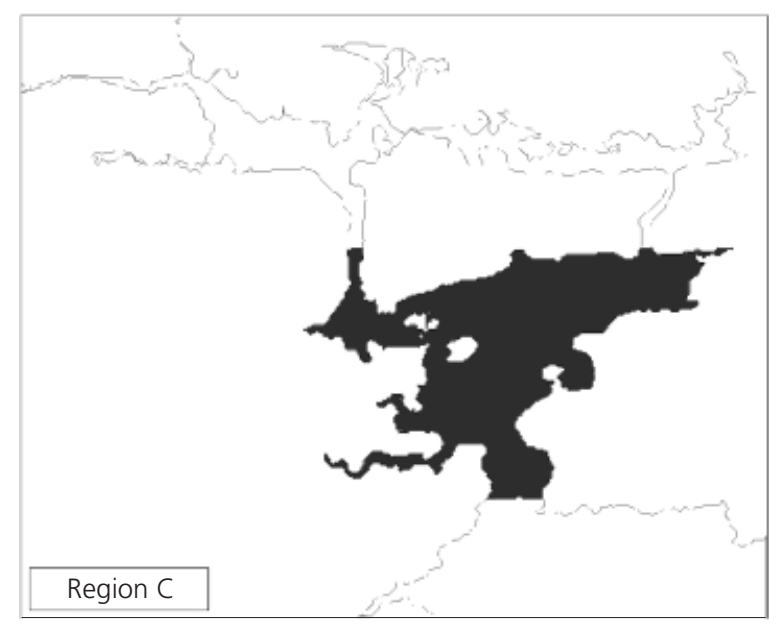

(iii)

(a)

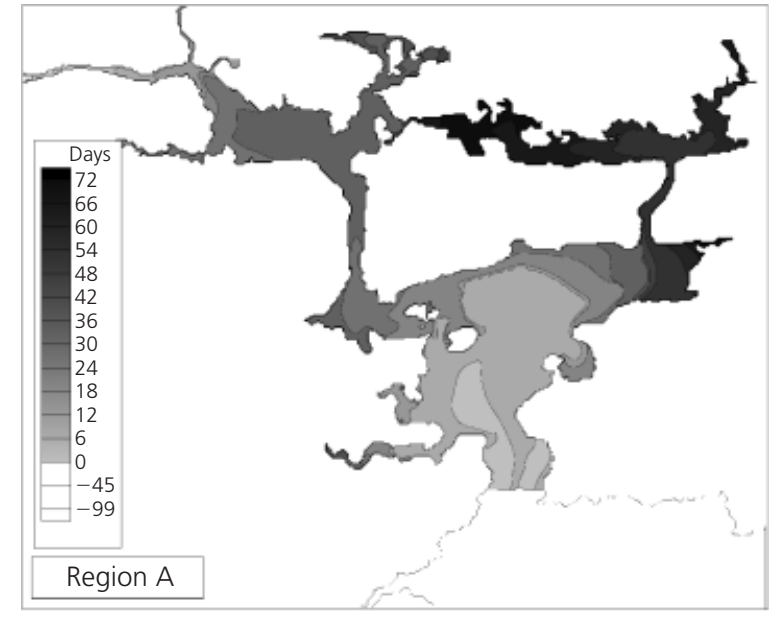

(i)

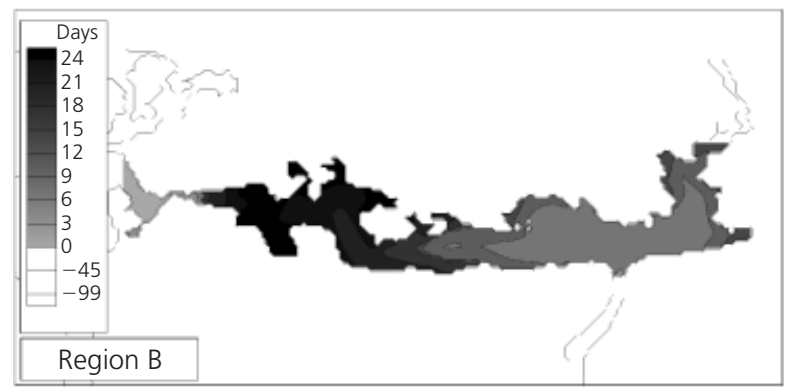

(ii)

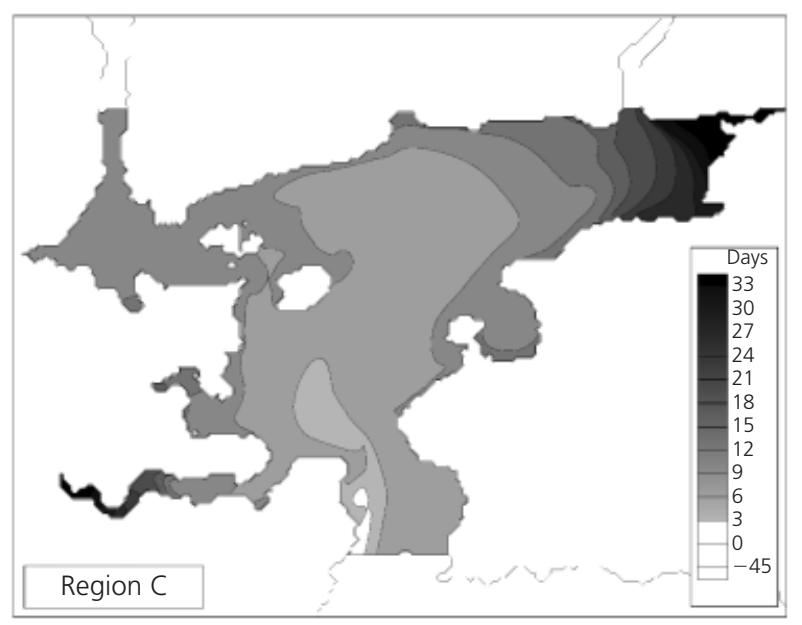

(iii)

(b)

Figure 14. (a) regions of Cork Harbour selected for flushing studies; (b) spatial distribution of residence times $\tau_{\mathrm{r}}$ computed for each region 


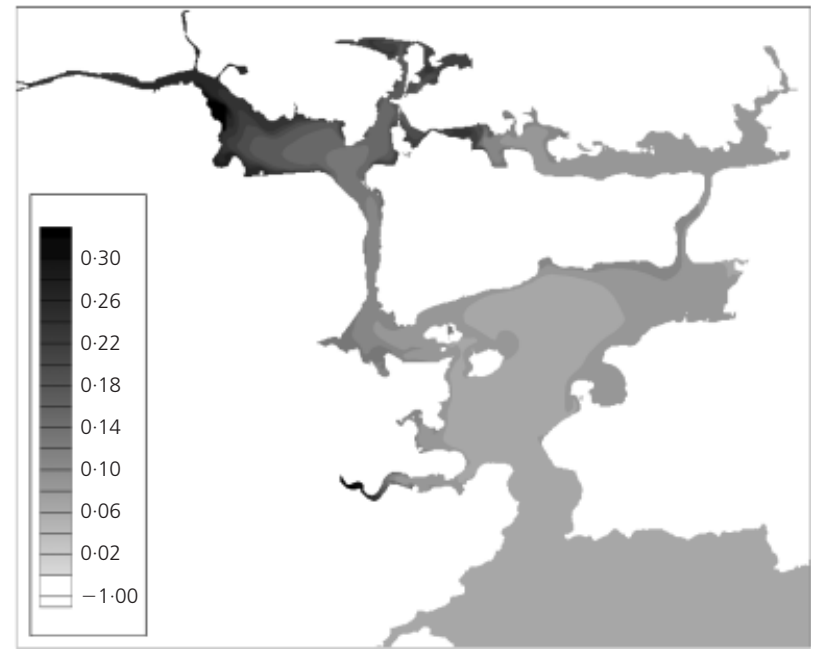

(a)

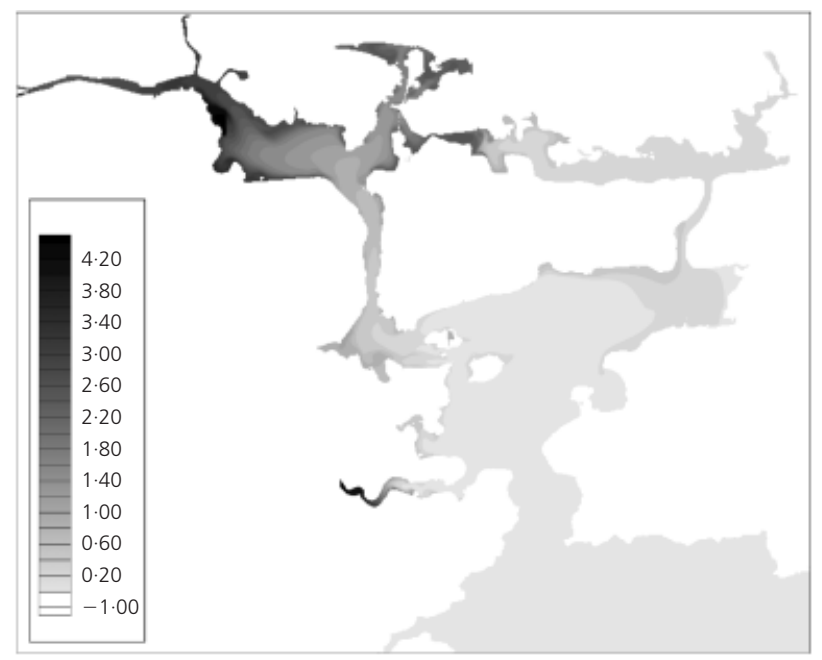

(b)

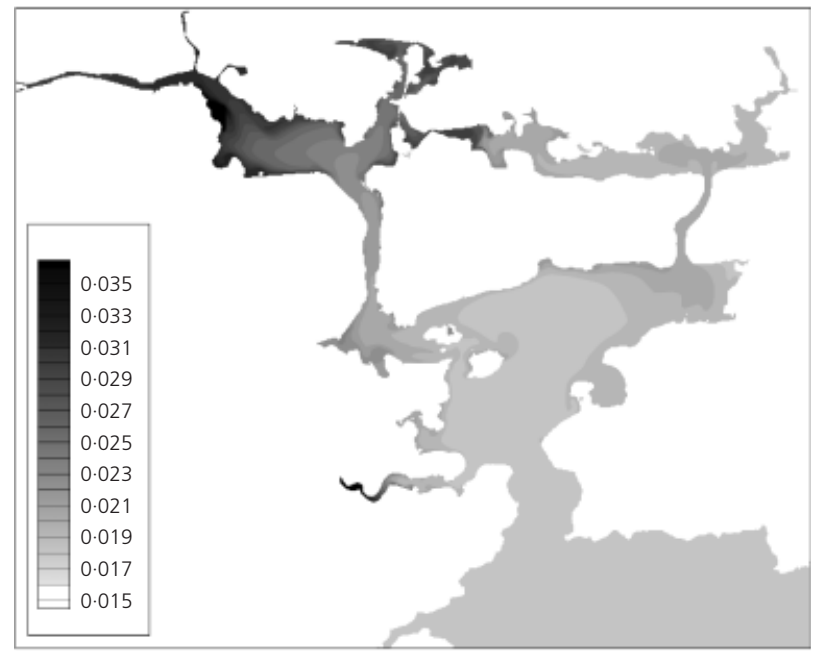

(c)

Figure 15. Initial condition grids (unit mg/l) for (a) ammonia, (b) nitrate nitrogen and (c) orthophosphate within a harbour. A rule of thumb for determining the limiting nutrient relates to the nitrogen:phosphorous $(\mathrm{N}: \mathrm{P})$ ratio (Chapra, 1997), which is approximately $7 \cdot 2$ for biomass. An N:P ratio in the water of less than $7 \cdot 2$ therefore suggests that nitrogen is limiting, while higher levels imply that phosphorous will limit plant growth (Chapra, 1997). Using the initial grids, the spatial variation of the available N:P ratio was plotted for the harbour (Figure 16). It was found that the ratio of available nitrogen (ammonia and nitrate) to available phosphorous (orthophosphate) was greater than 7.2 in Lough Mahon and the North Channel, suggesting that phytoplankton growth is phosphorous-limited. Generally, nitrogen is the limiting nutrient in coastal marine systems (Howarth and Marino, 2006). However, the EPA report on Irish water quality (McGarrigle et al., 2002) states that both Lough Mahon and the North Channel were found to be phosphorous-limited, thus confirming the above analysis. In the main harbour, the N:P ratio was less than $7 \cdot 2$, implying that nitrogen is the limiting nutrient in this area. Again, this agreed with the EPA findings for the same area where the majority of samples indicated that nitrogen was limiting. It is therefore useful to analyse the initial nutrient grids in terms of the $\mathrm{N}: \mathrm{P}$ ratio as they can gave an indication of the controlling nutrient for algal growth. However, any such indications should be treated with caution as the initial grids do not take account of the localised effects of nutrient inputs.

Figure 17 presents the monthly averaged data for waterbody temperature employed by the Cork model, while Figure 18 presents those for light intensity and photoperiod. Average water temperatures in Cork Harbour vary between $10^{\circ} \mathrm{C}$ in winter and $15^{\circ} \mathrm{C}$ in summer. Lower temperatures have the effect of reducing phytoplankton growth rates. Light availability (intensity $\times$ photoperiod) in the harbour ranges between approximately $10 \mathrm{Ly} /$ day in winter and $130 \mathrm{Ly} /$ day in summer; as with temperature, lower light availability also reduces the growth rate. For the phytoplank-

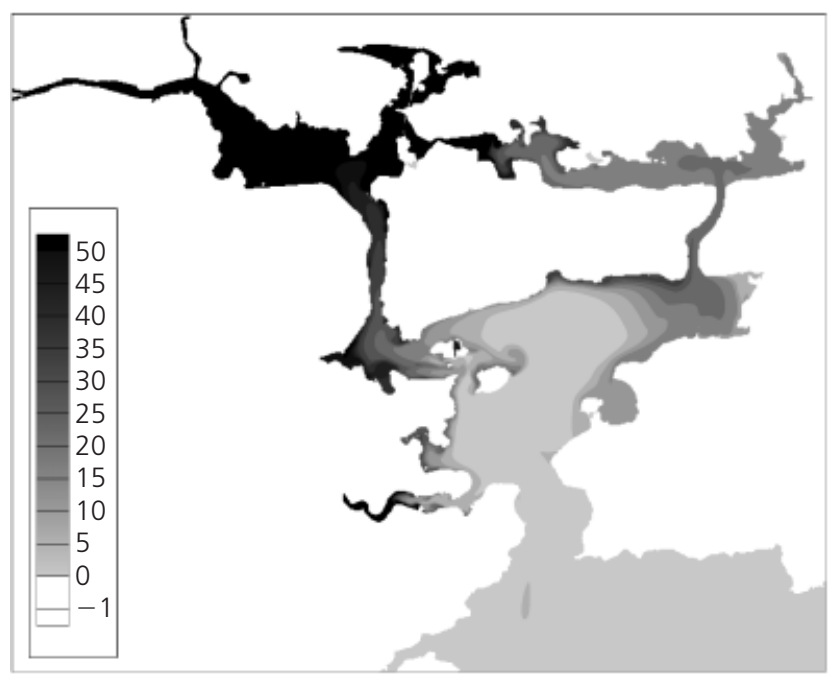

Figure 16. 'Available' N:P ratio calculated from initial grids 


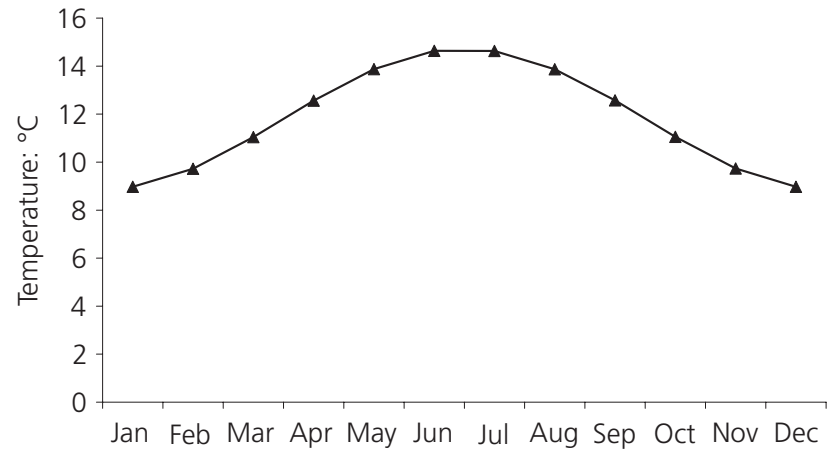

Figure 17. Monthly averaged waterbody temperature

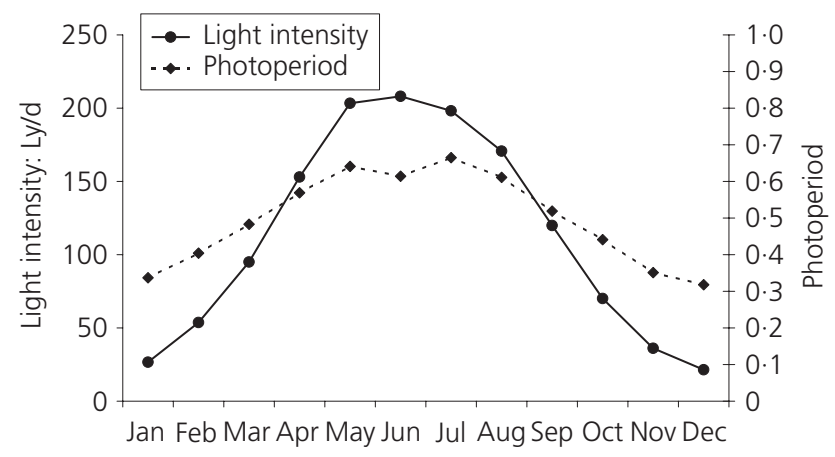

Figure 18. Monthly averaged light intensity and photoperiod

ton summer simulations, water temperature and light availability were approximately $12 \cdot 5^{\circ} \mathrm{C}$ and $62 \mathrm{Ly} /$ day.

Higher concentrations of suspended solids in estuarine waters result in greater light attenuation than in fresh or marine waters. The relatively low level of light availability in comparison with the ready availability of nutrients means that, generally, light rather than nutrients tends to be the limiting environmental factor. Brennan et al. (1998) and McMahon et al. (1992) also make this observation. In a modelling study of Wexford Harbour, Hartnett and Nash (2004) found that model predictions of chlorophyll-a were highly sensitive to light availability, reinforcing the previous hypothesis. Due to the importance of light limitation and its relationship with turbidity, a site-specific light attenuation function was developed for the Wexford model based on Secchi disc transparencies. Figure 19 compares model predictions of chlorophyll-a during July in Wexford Harbour using the model default light attenuation function and the site-specific function. EPAmeasured data for July 1998 are also shown (Neill, 1999). As can be seen, the use of the site-specific formulation resulted in much more accurate predictions.

Initially, the light attenuation coefficient $K_{\mathrm{A}}$ was incorporated in the model using the formulation of Brown and Barnwell (1987):

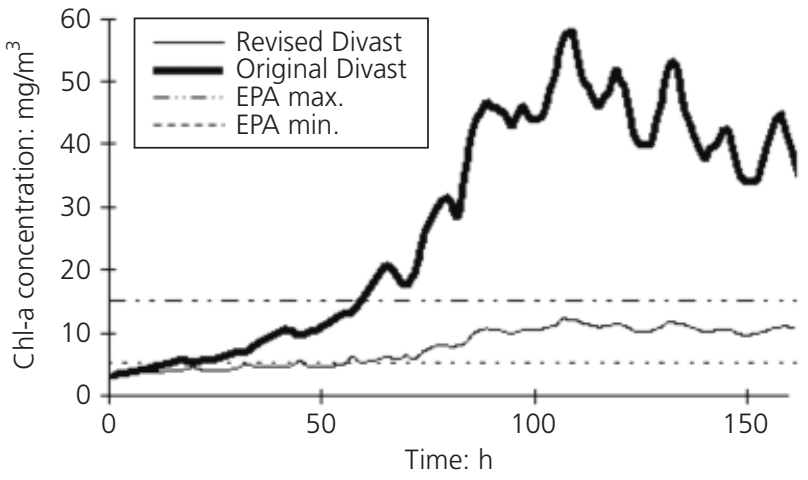

Figure 19. Model predictions of chlorophyll-a in Wexford Harbour using the model default and site-specific light attenuation functions. EPA measurements also shown (data obtained directly from Irish EPA)

7. $K_{\mathrm{A}}=0.09+0.0088\left(C_{\mathrm{P}}\right)+0.054\left(C_{\mathrm{P}}\right)^{2 / 3}$

Using this expression, initial model simulations considerably overpredicted chlorophyll-a levels within Cork Harbour. Light attenuation within a water column varies significantly from estuary to estuary based on turbidity and phytoplankton levels. Therefore, in order to incorporate this site-specific aspect, a new light attenuation relationship was developed for Cork Harbour. Following detailed analysis of recorded chlorophyll-a concentrations and Secchi disc readings, the following relationship was derived (see Costello et al. (2001) for more details):

\section{8. $K_{\mathrm{A}}=0.79012+0.004296\left(C_{\mathrm{P}}\right)$}

Figure 20 shows the improvement in chlorophyll-a predictions

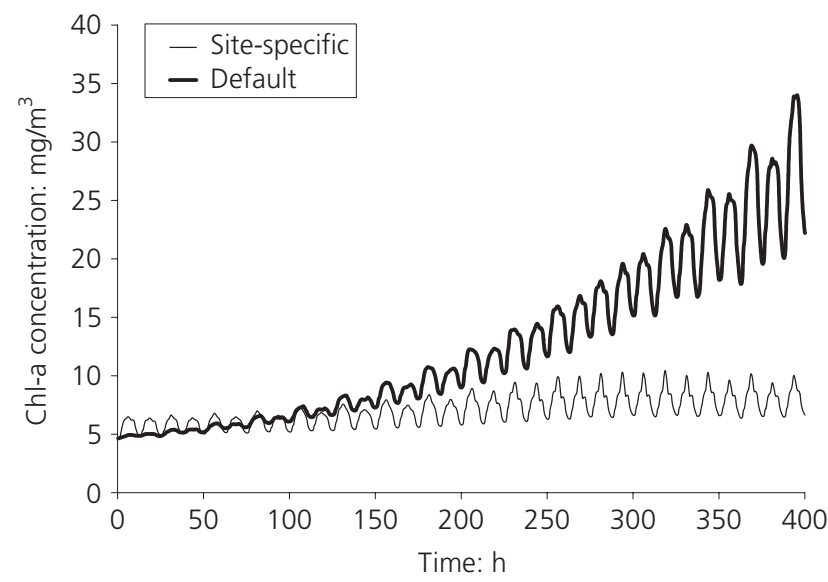

Figure 20. Model predictions of chlorophyll-a in Cork Harbour using the model default and site-specific light attenuation functions. Results shown for Marino Point (D1 on Figure 4) 
achieved using the site-specific formula at point D1 (see Figure 4) in the Cork Harbour model.

The final phytoplankton simulation was run for four complete spring-neap tidal cycles to develop steady-state conditions and to span summer and autumn seasons. Phytoplankton growth and transport were predicted based on harbour hydrodynamics, nutrient fluxes and environmental conditions. Chlorophyll-a concentrations calculated during September are shown in Figure 21 for spring high water, post steady state. Figure 22 shows the transect lines of remotely sensed chlorophyll-a concentrations for the same time. A number of good comparisons between the two sets of results can be observed. Upon examination of the recorded data, a number of areas with chlorophyll-a levels in excess of $6 \mathrm{mg} / \mathrm{m}^{3}$ are evident (areas 1-6 on Figures 21 and 22); most of

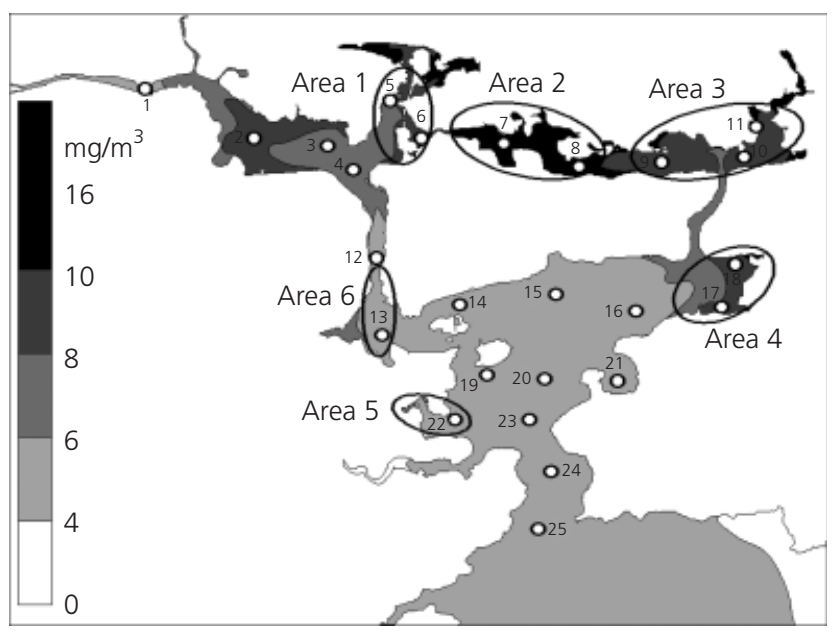

Figure 21. Predicted chlorophyll-a concentrations for spring high water, September and 25 validation locations

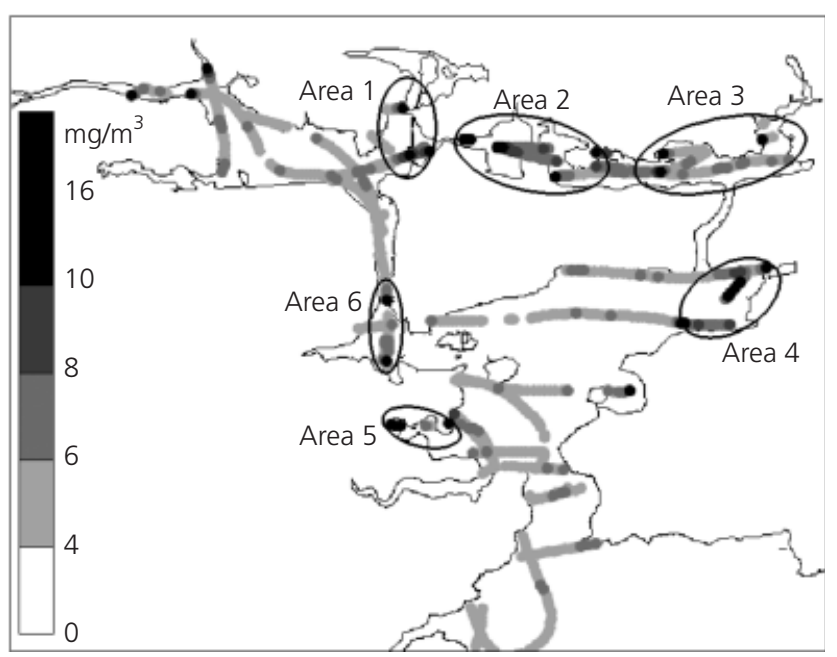

Figure 22. Remotely sensed chlorophyll-a concentrations for spring high water, September these areas are also observed in the model snapshot. Chlorophylla levels in the region of $10 \mathrm{mg} / \mathrm{m}^{3}$ were recorded in the area to the east of the main harbour, in the North Channel and to the west of the North Channel; these higher concentrations were also reproduced by the model. The highest concentrations of $>10 \mathrm{mg} / \mathrm{m}^{3}$ were recorded in the North Channel, and these concentrations computed by the model were located in the same area. For both the measured and modelled results, the chlorophyll-a levels in the well-flushed central portion of the main harbour are of a similar range, $4-5 \mathrm{mg} / \mathrm{m}^{3}$.

In contrast to the above, there are two particularly obvious discrepancies between the two sets of results. Firstly, the model does not predict the higher concentrations observed within area 5 in Figure 22; however, this anomaly is most likely due to a limitation of the remote sensing method used to record the chlorophyll-a concentrations. The remote sensing technology was found to experience problems in areas of exposed rocky shores, and area 5 is one such location. The rock surfaces tended to cause greater reflectance leading to the calculation of spurious, elevated chlorophyll-a levels. Field data verified the inaccuracy of the remotely sensed data in this area and results were more consistent with model predictions. Secondly, the area of higher concentrations predicted by the model in Lough Mahon is not as evident in the measured data. However, this may be explained, in part, by the fact that the remotely sensed data only relate to chlorophyll-a concentrations in the upper $2 \mathrm{~m}$ or less of the water column while those calculated by the model are depth averaged. Further explanation was provided by an analysis of field data, which indicated that limited stratification develops within Lough Mahon; higher concentrations of chlorophyll-a are present in the lower layers of the water column (Costello et al., 2001). This finding is significant as it demonstrates that remotely sensed results should be treated with caution in stratified regions, particularly as stratification occurs most often during the critical summer period for phytoplankton production.

In general, the model seemed to produce quite similar levels of chlorophyll-a. Modelled and measured concentrations were analysed at 25 locations (shown in Figure 21) using linear regression. The results of this analysis, shown in Figure 23, demonstrated a high level of correlation between the model results and the measured data. The results demonstrated that the model was capable of accurately predicting phytoplankton growth within the harbour.

Phytoplankton concentrations predicted by the model and recorded in the field were found to be highest in shallow-water areas with low hydrodynamic activity and, consequently, longer tidal flushing times. This is illustrated by comparing the chlorophyll-a predictions in Figure 21 with Figure 24, which shows the current velocities predicted by the model at mid-flood on a typical spring tide. In addition, most of the areas of high productivity correspond to the locations of domestic and industrial discharges or the mouths of rivers. The combination of long 


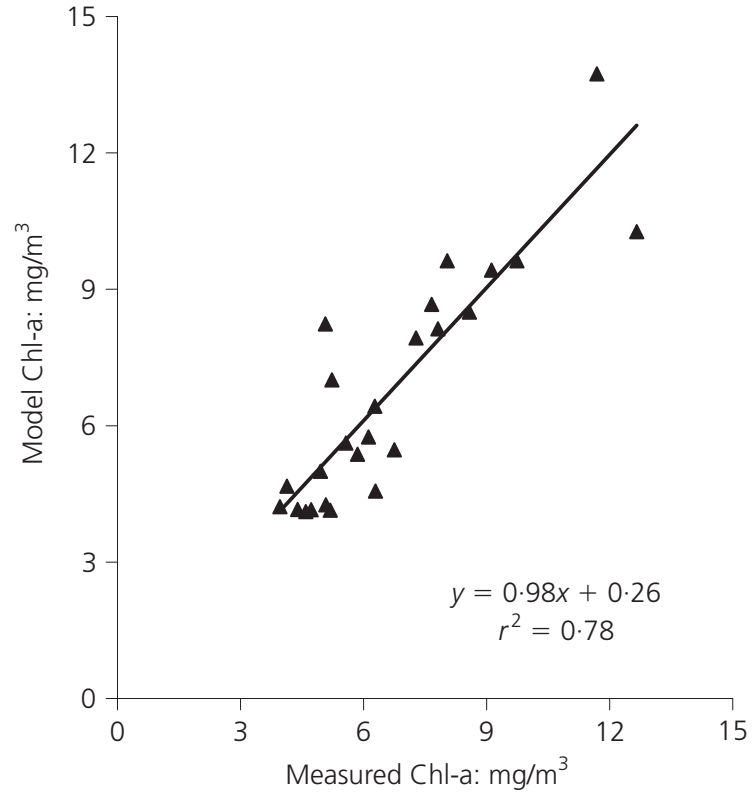

Figure 23. Linear regression analysis of the modelled and measured chlorophyll-a data presented in Figure 21 and Figure 22 respectively at the validation locations shown in Figure 21

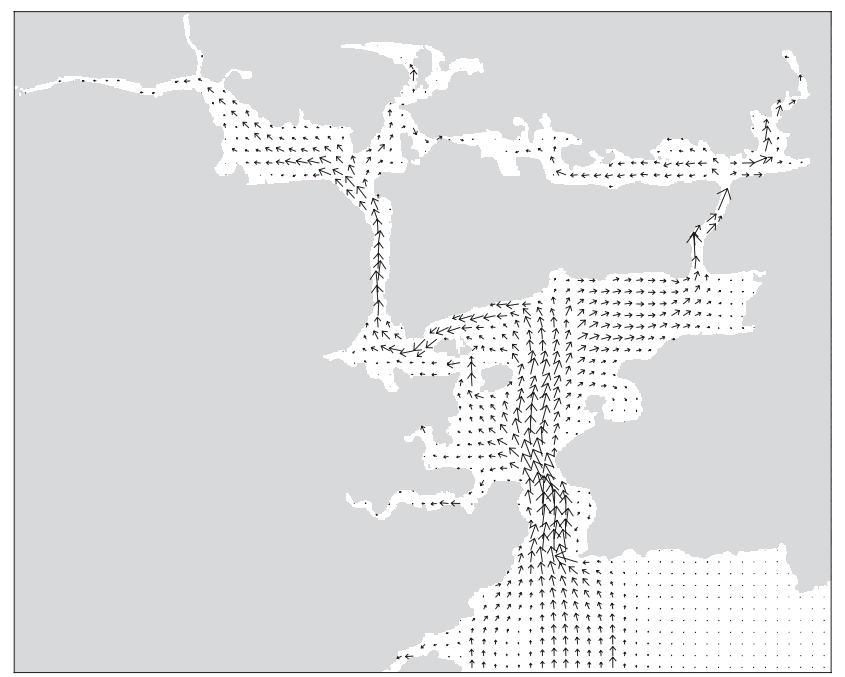

Figure 24. Current velocities predicted by model at mid-flood on a typical spring tide

flushing times and continuous nutrient inputs means that these areas are prime locations for elevated phytoplankton production. These same areas were identified during the flushing study as likely areas for increased phytoplankton production. Indeed, upon comparison of the spatial distribution of phytoplankton with that of residence time, a striking similarity can be observed. Figure 25 shows the same chlorophyll-a concentration plot as that in Figure 21 , the only difference being an increase in the number of contour intervals. When Figure 25 is compared with the spatial distribution of residence time for region A in Figure 14(b), it can

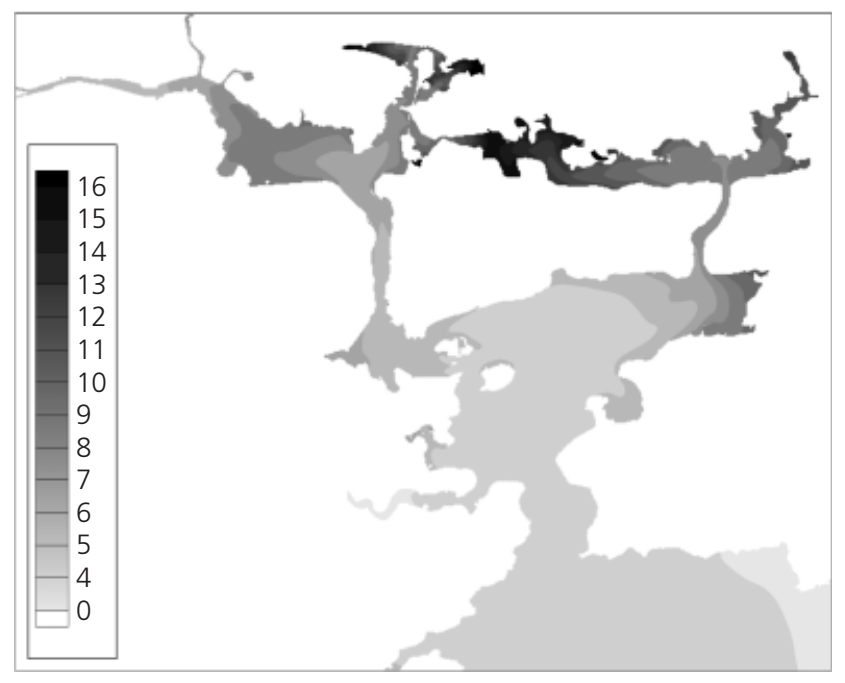

Figure 25. Predicted chlorophyll-a concentrations for spring high water, September

be seen that the areas of elevated chlorophyll-a levels match almost perfectly with the areas of higher residence times. This suggests that water residence time plots such as those shown in Figure 14 may represent a faster, more cost-effective method of identifying potential eutrophic waters in (or without) the development of a full water quality model. It also demonstrates the importance of gaining a full understanding of circulation/flushing patterns within a waterbody, particularly with the intention of identifying sub-regions of similar characteristics.

The model results indicated that the Lough Mahon sub-region had elevated levels of chlorophyll-a between 8 and $10 \mathrm{mg} / \mathrm{m}^{3}$. This is a particularly important region within Cork Harbour as it is the recipient of a number of nutrient inputs and algal blooms regularly develop here. This sub-region has poor tidal exchange, as evidenced in Figure 14(b), even though its flushing is aided by freshwater flow from the River Lee. The poor flushing is also evident from the initial condition nutrient grids (Figure 15) where concentrations of nutrients can be seen to be much higher within Lough Mahon than other parts of the harbour. Given the ready availability of nutrients, poor tidal flushing and favourable summer environmental conditions, it was therefore to be expected that Lough Mahon should (and does) experience elevated levels of phytoplankton during September. However, as mentioned previously, the elevated levels in this area were not recorded by the remote sensing equipment and model accuracy was therefore initially questioned. The analysis of the flushing study data and the initial grids led to additional sampling of the area, which vindicated the model predictions. This highlights the importance of an integrated approach to water quality modelling and the benefits of accurate specification of initial/boundary conditions and other model input.

It has already been demonstrated how spatial distribution of 
residence times can be used to identify transport pathways; these pathways are particularly important in terms of phytoplankton growth dynamics. If a body of water that has become nutrientenriched (or even eutrophic) flushes into a second body of water with a high residence time, the nutrients and algae will be retained in the second waterbody resulting in the potential development of eutrophic conditions in that area. This has significant implications for the siting of domestic and industrial outfalls. A good example may be observed by comparing the model chlorophyll-a results in Figure 21 with the residence times in Figure 14(b). It can be seen that water from the North Channel, which suffers from elevated chlorophyll-a levels, is flushed through Passage East into the eastern bay of the Main Channel. The long residence time of these receiving waters (50-60 days) and the nutrient and algal inputs from the North Channel (via Passage East) have led to elevated levels of chlorophyll-a in the area. Although a sewage treatment plant discharges to this area, its discharge is relatively low and is not sufficient to cause or sustain the elevated levels of phytoplankton growth that were recorded in this region.

Finally, the phytoplankton results also demonstrated the benefit of specifying initial condition grids to a water quality model. The beneficial effect is apparent when comparing the chlorophyll-a predictions in Figure 21 with the initial nutrient levels in Figure 15. The areas of elevated phytoplankton growth match quite closely those areas of elevated nutrient levels. Due to the more accurate representation of initial conditions at a particular time of the year, initial condition grids 'nudge' the model towards the correct solution. By pushing the model in the right direction, the final steady-state solution is not only more accurate but it is arrived at much more quickly.

\section{Conclusions}

A methodology has been developed with which to perform accurate and efficient assessment of the primary production of estuaries. The approach was applied, with success, to the complex brackish waters of Cork Harbour. The main conclusions drawn from this research can be summarised as follows.

(a) Although generic differential equations have been developed to describe water circulation and biogeochemical processes within estuaries, site-specific data are fundamental to accurately simulate the dynamics of primary production within an estuary. During the initial stages of this research, a published formulation for light attenuation with water depth was used in the governing equation for the growth of chlorophyll-a; this resulted in poor model predictions. Using data acquired during the project, a site-specific light attenuation formulation was developed, and this dramatically improved the model predictions. The light attenuation formulation is based on feedback related to chlorophyll-a concentration; determination of this in the field is easy and thus can be developed at relatively low cost for an estuary. Estuaries where suspended sediments dominate, however, may also require inclusion of a term relating light attenuation to sediment concentrations.

(b) Site-specific data were also found to be extremely important in the development of the initial grids. Through assimilating initial grids into the simulations, model efficiency and accuracy were both improved. The use of these grids proved to be extremely useful throughout this research and the authors recommend this approach to water quality modellers.

(c) Along with validating hydrodynamic and solute transport modules as usual, this research provided some validation of the primary production module. In this instance, remote airborne sensing was used. Using this approach, distributions of chlorophyll-a in the water surface were calculated for large sections of Cork Harbour over a short time interval. This enabled model predictions to be compared with estuary-wide in situ values at particular stages of the tide; this is quite unusual, but very beneficial for model validation. During this process it was shown that the model produced accurate predictions of spatially varying chlorophyll-a concentrations over Cork Harbour. Remote sensing is a very valuable tool that should be used more frequently in water quality modelling research.

(d) Flushing analysis was also carried out during this research, and the results obtained were very instructive. Pathways of pollutant transport were identified and they illustrated that, depending on the spatial variation in flushing characteristics, high levels of chlorophyll-a may be found in areas with high retention times that receive nutrients, via the transport pathways, from other areas of nutrient discharges. Contours of iso-flushing times also correlated well with contours of chlorophyll-a concentrations. Therefore, in the early stages of a water quality project, flushing studies can be used for preliminary evaluations.

(e) Where sufficient data exist, water quality models can be used to make efficient and effective contributions to water quality management of estuaries.

\section{Acknowledgements}

The authors would like to thank the many organisations that contributed to this research project. In particular, the authors thank the Irish Environmental Protection Agency for funding this research under the Environmental Monitoring, R\&D SubProgramme, Operational Programme for Environmental Sciences, and also for making data available to them. The authors also thank Wexford County Council, Cork County Council, The Irish Marine Institute and Cork City Council for their data.

\section{REFERENCES}

Bowie GL, Mills WB, Porcella DB et al. (1985) Rates, Constants, and Kinetic Formulations in Surface Water Quality Modelling. Environmental Research Laboratory, US EPA, Washington, DC. 
Brennan MT, Khan J, Jeffrey DW, Jennings E and Wilson JG (1998) The impacts of nutrients in an estuarine system. In Eutrophication in Irish Waters (Wilson JG (ed.)). Royal Irish Academy, Dublin, Ireland.

Brown LC and Barnwell TO (1987) The Enhanced Stream Water Quality Models QUAL2E and QUAL2E-UNCAS:

Documentation and User Manual. US EPA, Washington, DC. Chapra SC (1997) Surface Water Quality Modelling. McGrawHill, Singapore.

Costello MJ, Hartnett M, Mills P et al. (2001) Nutrient Dynamics of Two Estuaries in Ireland: Wexford and Cork Harbours. Irish EPA, Wexford, Ireland.

De Souza R-M (2004) Harmonizing population and coastal resources in the Philippines. World Watch Magazine 17(5): 38-40.

EEA (European Environment Agency) (2001) Eutrophication in Europe's coastal waters. EEA, Copenhagen, technical report $7 / 2001$.

Falconer RA, Lin B, Wu Y and Harris E (2001) DIVAST Reference Manual. Environmental Water Management Research Centre, Cardiff University.

Hartnett M and Nash S (2004) Modelling nutrients and chlorophyll-a dynamics in an Irish brackish waterbody. Environmental Modelling and Software 19(1): 47-56.

Hipsey MR, Antenucci JP, Romero JR and Hamilton D (2007) Dynamics Model: CAEDYM v3 v3.1 Science Manual. Centre for Water Research, University of Western Australia.
Howarth RW and Marino R (2006) Nitrogen as the limiting nutrient for eutrophication in coastal marine ecosystems: evolving views over three decades. Limnology and Oceanography 51(1/2): 364-376.

Marine Institute (1999) Ireland's Marine and Coastal Areas and Adjacent Seas: An Environmental Assessment. Marine Institute, Dublin.

McGarrigle ML, Bowman JJ, Clabby KJ et al. (2002) Water Quality in Ireland 1998-2000. Irish EPA, Wexford, Ireland.

McMahon TG, Raine RCT, Fast T, Kies L and Patching JW (1992) Phytoplankton biomass, light attenuation and mixing in the Shannon Estuary, Ireland. Journal of the Marine Biological Association (UK) 72(3): 709-720.

Murakami K (1991) Tidal exchange mechanisms in enclosed regions. Proceedings of the 2nd International Conference on Hydraulic and Environmental Modelling of Coastal Estuarine and River Waters, Bradford, Ashgate Publishing, Surrey, UK. 2, 111-120.

Neill M (1999) Water Quality in the Slaney Estuary and Wexford Harbour, Summer 1998. Irish EPA, Wexford, Ireland.

O'Sullivan MC (1977) Cork Harbour Pollution Report: A Report to Cork County Council. Cork Corporation and Cork Harbour Commissioners, Cork, Ireland, vol. I-XVII.

Takeoka H (1984) Fundamental concepts of exchange and transport timescales in a coastal sea. Continental Shelf Research 3(3): 311-326.

\section{WHAT DO YOU THINK?}

To discuss this paper, please email up to 500 words to the editor at journals@ice.org.uk. Your contribution will be forwarded to the author(s) for a reply and, if considered appropriate by the editorial panel, will be published as a discussion in a future issue of the journal.

Proceedings journals rely entirely on contributions sent in by civil engineering professionals, academics and students. Papers should be $2000-5000$ words long (briefing papers should be 1000-2000 words long), with adequate illustrations and references. You can submit your paper online via www.icevirtuallibrary.com/content/journals, where you will also find detailed author guidelines. 